\title{
Probing the Carbon-Hydrogen Activation of Alkanes Following Photolysis of Tp'Rh(CNR)(carbodiimide): A Computational and Time-resolved Infrared Spectroscopic Study
} Jia Guan, Alisdair Wriglesworth, Xue Zhong Sun, Edward N. Brothers, Snezana D. Zaric, Meagan E. Evans, William D. Jones, Michael Towrie, Michael B. Hall, and Michael W. George J. Am. Chem. Soc., Just Accepted Manuscript • DOI: 10.1021/jacs.7b12152 • Publication Date (Web): 31 Dec 2017

Downloaded from http://pubs.acs.org on December 31, 2017

\section{Just Accepted}

"Just Accepted" manuscripts have been peer-reviewed and accepted for publication. They are posted online prior to technical editing, formatting for publication and author proofing. The American Chemical Society provides "Just Accepted" as a free service to the research community to expedite the dissemination of scientific material as soon as possible after acceptance. "Just Accepted" manuscripts appear in full in PDF format accompanied by an HTML abstract. "Just Accepted" manuscripts have been fully peer reviewed, but should not be considered the official version of record. They are accessible to all readers and citable by the Digital Object Identifier (DOI®). "Just Accepted" is an optional service offered to authors. Therefore, the "Just Accepted" Web site may not include all articles that will be published in the journal. After a manuscript is technically edited and formatted, it will be removed from the "Just Accepted" Web site and published as an ASAP article. Note that technical editing may introduce minor changes to the manuscript text and/or graphics which could affect content, and all legal disclaimers and ethical guidelines that apply to the journal pertain. ACS cannot be held responsible for errors or consequences arising from the use of information contained in these "Just Accepted" manuscripts. 


\title{
Probing the Carbon-Hydrogen Activation of Alkanes Following Photolysis of Tp'Rh(CNR)(carbodiimide): A Computational and Time-resolved Infrared Spectroscopic Study
}

\author{
Jia Guan, ${ }^{\dagger}$ Alisdair Wriglesworth,${ }^{\ddagger}$ Xue Zhong Sun,${ }^{\ddagger}$ Edward N. Brothers, ${ }^{\&}$ Snežana D. \\ Zarić, ${ }^{\&}$ Meagan E. Evans, ${ }^{\#}$ William D. Jones, ${ }^{\#}$ Michael Towrie, ${ }^{\%}$ Michael B. Hall, ${ }^{* \dagger}$ and \\ Michael W. George*,\$, \\ †Department of Chemistry, Texas A\&M University, College Station, TX 77843-3255, USA \\ ${ }^{\ddagger}$ School of Chemistry, University of Nottingham, University Park NG7 2RD, UK \\ ${ }^{\&}$ Science Program, Texas A\&M University at Qatar, P. O. Box 23874, Doha, QATAR \\ 'Department of Chemistry, University of Belgrade, Belgrade, SERBIA \\ \#Department of Chemistry, University of Rochester, Rochester, NY 14627, USA \\ ${ }^{\%}$ Central Laser Facility, Research Complex at Harwell, Rutherford Appleton Laboratory, \\ Chilton, Oxfordshire OX11 0QX, UK \\ ${ }^{\S}$ Department of Chemical and Environmental Engineering, University of Nottingham Ningbo \\ China, 199 Taikang East Road, Ningbo 315100, CHINA
}

\begin{abstract}
Carbon-hydrogen bond activation of alkanes by $\operatorname{Tp}^{\prime} \operatorname{Rh}(\mathrm{CNR}) \quad\left(\mathrm{Tp} \mathrm{p}^{\prime}=\mathrm{Tp}=\right.$ trispyrazolylborate or $\mathrm{Tp}^{*}=\operatorname{tris}(3,5$-dimethylpyrazolyl)borate) were followed by timeresolved infrared spectroscopy (TRIR) in the $v(\mathrm{CNR})$ and $v(\mathrm{BH})$ spectral regions on $\mathrm{Tp} * \mathrm{Rh}\left(\mathrm{CNCH}_{2} \mathrm{CMe}_{3}\right)$, and their reaction mechanisms were modelled by density functional theory (DFT) on $\mathrm{TpRh}(\mathrm{CNMe})$. The major intermediate species were: $\kappa^{3}-\eta^{1}$-alkane complex (1); $\kappa^{2}-\eta^{2}$-alkane complex (2); and $\kappa^{3}$-alkyl hydride (3). Calculations predict that the barrier between $\mathbf{1}$ and $\mathbf{2}$ arises from a triplet-singlet crossing and intermediate $\mathbf{2}$ proceeds over the rate-determining $\mathrm{C}-\mathrm{H}$ activation barrier to give the final product 3 . The activation lifetimes


measured for the $\mathrm{Tp} * \mathrm{Rh}(\mathrm{CNR})$ and $\mathrm{Tp} * \mathrm{Rh}(\mathrm{CO})$ fragments with $n$-heptane and four cycloalkanes $\left(\mathrm{C}_{5} \mathrm{H}_{10}, \mathrm{C}_{6} \mathrm{H}_{12}, \mathrm{C}_{7} \mathrm{H}_{14}\right.$, and $\left.\mathrm{C}_{8} \mathrm{H}_{16}\right)$ increase with alkanes size and show a dramatic increase between $\mathrm{C}_{6} \mathrm{H}_{12}$ and $\mathrm{C}_{7} \mathrm{H}_{14}$. A similar step-like behaviour was observed previously with $\mathrm{CpRh}(\mathrm{CO})$ and $\mathrm{Cp}^{*} \mathrm{Rh}(\mathrm{CO})$ fragments and is attributed to the wider difference in $\mathrm{C}-\mathrm{H}$ bonds that appear at $\mathrm{C}_{7} \mathrm{H}_{14}$. However, $\mathrm{Tp} \mathrm{R}^{\prime} \mathrm{Rh}(\mathrm{CNR})$ and $\mathrm{Tp} \mathrm{R}^{\prime} \mathrm{Rh}(\mathrm{CO})$ fragments have much longer absolute lifetimes compared to those of $\mathrm{CpRh}(\mathrm{CO})$ and $\mathrm{Cp} * \mathrm{Rh}(\mathrm{CO})$ fragments, because the reduced electron density in dechelated $\kappa^{2}-\eta^{2}$-alkane Tp' complexes stabilizes the $d^{8} \mathrm{Rh}(\mathrm{I})$ in a square-planar geometry and weakens the metal's ability for oxidative addition of the $\mathrm{C}-\mathrm{H}$ bond. Further, the $\mathrm{Tp}$ ' $\mathrm{Rh}(\mathrm{CNR})$ fragment has significantly slower rates of $\mathrm{C}-\mathrm{H}$ activation in comparison to the $\mathrm{Tp}$ ' $\mathrm{Rh}(\mathrm{CO})$ fragment for the larger cycloalkanes, because the steric bulk of the neopentyl isocyanide ligand hinders the rechelation in $\kappa^{2}$-Tp'Rh(CNR)(cycloalkane) species and results in the $\mathrm{C}-\mathrm{H}$ activation without the assistance of the rechelation.

\section{Introduction}

The control of organometallic reactions is a complex interplay between sterics and electronics. ${ }^{1}$ Even though the $\mathrm{C}-\mathrm{H}$ activation of alkanes by rhodium complexes such as $\mathrm{Cp}^{\prime} \mathrm{Rh}(\mathrm{CO})_{2}\left(\mathrm{Cp}^{\prime}\right.$ is $\mathrm{Cp}=\mathrm{C}_{5} \mathrm{H}_{5}$ or $\left.\mathrm{Cp}^{*}=\mathrm{C}_{5} \mathrm{Me}_{5}\right)$ and $\mathrm{Tp} \mathrm{Rh}(\mathrm{CO})_{2}$ (Tp' is $\mathrm{Tp}=$ tris(pyrazolyl)borate), $\mathrm{Tp}^{*}=\operatorname{tris}(3,5$-dimethylpyrazolyl $)$ borate $)$, or $\mathrm{Tp}^{\mathrm{tBu}}=\operatorname{tris}(3,5$-dimethyl 4-t-butylpyrazolyl)borate)) has been extensively studied ${ }^{2-8}$, understanding all of the factors that control the barriers to activation and how these depend upon the nature of the metal centre and the alkane is still incomplete. A full understanding of this important reaction has been limited because of complications that include the varying strength of structurally different $\sigma$-bonded alkane complexes, electronic and steric barriers to activation over a number of closely related but different barriers, and whether the barriers for migration to 
alternative $\mathrm{C}-\mathrm{H}$ activation sites are higher or lower than activation barrier thereby providing slower or faster routes to additional $\sigma$-bonded alkane complexes as resting states.

Previous experimental and theoretical reports have provided insight into answering some of these questions. ${ }^{2-8} \mathrm{Cp}$ ' $\mathrm{Rh}(\mathrm{CO})($ alkane) forms the alkyl hydride $\mathrm{Cp}$ ' $\mathrm{Rh}(\mathrm{CO})(\mathrm{R}) \mathrm{H}$ rapidly on the 1-20 ns timescale depending on the alkanes. ${ }^{3}$ Varying the nature of the alkane from methane to decane showed a nearly linear increase with respect to the alkane which was initially surprising because a difference was expected upon the introduction of secondary C-H i.e. going from ethane to propane. A more pronounced clearly oscillatory behaviour upon changing the alkane was observed for $\mathrm{Cp} * \mathrm{Rh}(\mathrm{CO})($ alkane) and an understanding of the barriers to primary and secondary alkane activation, the rates of 1,2- and 1,3-migrations of the coordination centre along the chain, and the importance of the conformation (trans vs. gauche) of the coordinated alkane is required in order to predict the behavior of these reactions. In other words, the observed variation in lifetimes arises from a subtle competition between activation and migration rates for truly linear alkanes being 1,3-migrations $>1,2$ migrations $>$ primary $\mathrm{C}-\mathrm{H}$ activation $>$ secondary $\mathrm{C}-\mathrm{H}$ activation. Longer alkanes such as decane have a tendency to fold upon themselves in solution and this additional complexity makes unraveling the behavior of these more sterically crowed systems difficult. Studies on the activation of $\mathrm{Cp}^{\prime} \mathrm{Rh}(\mathrm{CO})\left(\right.$ alkane) for cyclic alkanes $\left(\mathrm{C}_{5} \mathrm{H}_{10}, \mathrm{C}_{6} \mathrm{H}_{12}, \mathrm{C}_{7} \mathrm{H}_{14}\right.$, and $\left.\mathrm{C}_{8} \mathrm{H}_{16}\right)$ showed an unexpectedly large increase in the lifetimes of the $\sigma$-complexes from cyclohexane to cycloheptane. ${ }^{4,5}$ It was concluded that the different $\mathrm{C}-\mathrm{H}$ bonds formed a range of $\sigma$ complex stabilities and activation barriers, and these ranges widen with ring size and it is this large number of inequivalent $\mathrm{C}-\mathrm{H}$ bonds and the larger steric crowding for the cycloheptane ring that leads to its large increase in lifetime. There have also been extensive studies ${ }^{6-8}$ on the activation of related $\mathrm{Tp}$ ' $\mathrm{Rh}(\mathrm{CO})\left(\right.$ alkane) where two distinct $\sigma$-complexes were observed ${ }^{6}$ that were identified as $\kappa^{3}-\mathrm{Tp}{ }^{\prime} \operatorname{Rh}(\mathrm{CO})\left(\right.$ alkane) and $\kappa^{2}-\mathrm{Tp}{ }^{\prime} \mathrm{Rh}(\mathrm{CO})\left(\right.$ alkane) ${ }^{7}$, where the latter 
has one arm of the Tp' ligand dechelated as a result of loss of a $\mathrm{CO} \pi$-acceptor from the parent $\mathrm{Tp}$ ' $\mathrm{Rh}(\mathrm{CO})_{2}$, which is key to stabilizing the $d^{8} \sigma$-complexes. ${ }^{7-8}$ The activation of the $\mathrm{C}-\mathrm{H}$ bond occurs on a slower timescale compared to the analogous $\mathrm{Cp}$ ' $\mathrm{Rh}(\mathrm{CO})($ alkane) complexes. Initial interpretations reported that $\mathrm{C}-\mathrm{H}$ activation occurs to form $\kappa^{2}$ Tp'Rh(CO)(alkyl)H but subsequent studies suggested that prior recoordination was essential to lowering the barrier for $\mathrm{C}-\mathrm{H}$ activation. ${ }^{8}$ However, these studies only examined a limited number of linear alkanes. Although fast time-resolved studies have not been reported for $\mathrm{Tp} * \mathrm{Rh}(\mathrm{CNR})($ alkane), activation and reductive elimination for small linear alkane complexes have been studied both experimentally and computationally, where the results parallel those of $\mathrm{Tp} * \mathrm{Rh}(\mathrm{CO})\left(\right.$ alkane). ${ }^{9-12}$

In this paper we investigate the photochemistry of $\mathrm{Tp} * \mathrm{Rh}(\mathrm{CNR})$ (carbodiimide) in cyclic alkanes in order to elucidate the factors controlling the stability and activation of alkanes to Tp' versus Cp' complexes and the interplay between activation by $\kappa^{2}-\mathrm{Tp}$ 'RhL(alkane) and $\kappa^{3}-$ Tp'RhL(alkane) and how the sterics and electronics govern this important reaction.

\section{Results and discussion}

Initially, the photochemistry of $\mathrm{Tp} * \mathrm{Rh}(\mathrm{CNR})$ (carbodiimide) in $n$-heptane was studied using TRIR spectroscopy and DFT calculations, following the process of the activation of heptane as well as other processes observed at earlier time measurements. The detailed study of $n$ heptane established appropriate computational methodology capable of complementing the experimental data. Then this combination of experimental and theoretical methodology was used to study the photochemical reaction of $\mathrm{Tp} * \mathrm{Rh}(\mathrm{CNR})$ (carbodiimide) in cycloalkanes.

\section{Photochemistry of Tp*Rh(CNR)(carbodiimide) in $n$-heptane}


TRIR spectroscopy of the activation of $\boldsymbol{n}$-heptane. The $T p^{*} \mathrm{Rh}(\mathrm{CNR})$ (carbodiimide) $(\mathrm{R}=$ neopentyl) compound has two important infrared active groups: an isocyanide (CNR) and a B-H, which are present in $n$-heptane at 2178 and $2524 \mathrm{~cm}^{-1}$, respectively (see Table 1). CNR is a $\pi$-acceptor group bound to the metal through the carbon and can act as a reporter group, which has been followed by TRIR spectroscopy. Additionally, the v(B-H) band in the IR can provide additional information to aid the elucidation of the mechanism of $\mathrm{C}-\mathrm{H}$ activation as it reports on the coordination $\left(\kappa^{2}\right.$ or $\left.\kappa^{3}\right)$ of the $\mathrm{Tp} *$ ligand to the rhodium centre, Figure 1.

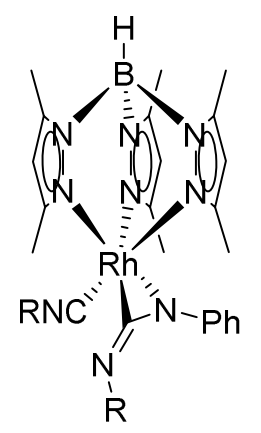

Figure 1: Structure of $T p * \operatorname{Rh}(\mathrm{CNR})($ carbodiimide).

The ps-TRIR spectra obtained in the isocyanide spectral region after $355 \mathrm{~nm}$ photolysis of $\mathrm{Tp} * \mathrm{Rh}(\mathrm{CNR})$ (carbodiimide) in $n$-heptane is shown in Figure 2(a). The TRIR spectrum obtained 1 ps after irradiation clearly shows that the parent band at $2178 \mathrm{~cm}^{-1}$ is bleached together with the production of several positive peaks relating to the formation of new species. A major transient band at $2076 \mathrm{~cm}^{-1}$ was also observed, which undergoes a small shift to $2083 \mathrm{~cm}^{-1}$ due to vibrational cooling over $c a .15 \mathrm{ps}$. This band, referred to as species 1, decays away $[\tau=430( \pm 30) \mathrm{ps}]$ at the same rate a new peak at $2108 \mathrm{~cm}^{-1}$ (referred to as species 2) grows in $[\tau=360( \pm 60)$ ps], Figure 2(c). All of the observed $v(C N R)$ frequencies of the major species are summarised in Table 1. A number of species at low concentrations observed in the early time but not included in Table 1 are discussed in the next section. The conversion of $\mathbf{1}$ to $\mathbf{2}$ appears to fit with a dechelation step from a $\kappa^{3}-\mathrm{Tp} \mathrm{p}^{*}$ intermediate to a $\kappa^{2}$ - 
Tp* species, similarly observed with $\mathrm{Tp}^{\prime} \mathrm{Rh}(\mathrm{CO})_{2}$ in previous time-resolved IR experiments. ${ }^{7,8}$ As one of the pyrazolyl arms dechelates, removing electron density from the metal, back-donation into the CNR anti-bonding orbitals decreases and the CNR bonding is strengthened. Therefore, a $\kappa^{3} \rightarrow \kappa^{2}$ dechelation step is consistent with the observed increase in $v(C N R)$ frequency from 2083 to $2108 \mathrm{~cm}^{-1}$. The measured lifetimes for the conversion of $\mathbf{1}$ to 2 are also on a similar timescale to the lifetimes observed with $T p ' R h(C O)_{2}$, again consistent with a $\kappa^{3} \rightarrow \kappa^{2}$ dechelation step. ${ }^{7,8}$ We therefore tentatively assign 1 to be $\kappa^{3}$ $\mathrm{Tp} * \mathrm{Rh}(\mathrm{CNR})\left(\right.$ alkane) and 2 to be $\kappa^{2}-\mathrm{Tp} * \mathrm{Rh}(\mathrm{CNR})($ alkane).
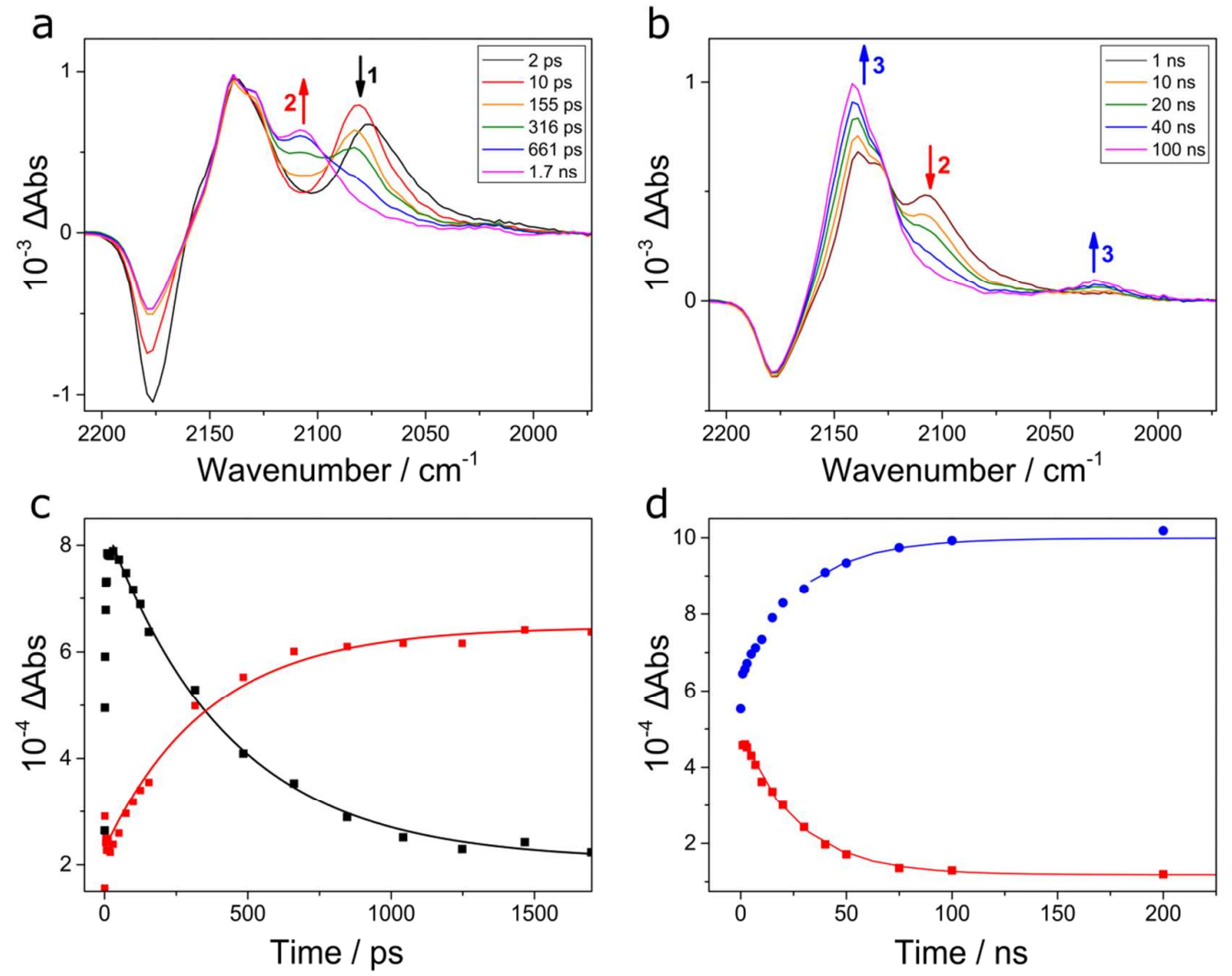

Figure 2: Photolysis (355 $\mathrm{nm}$ ) of Tp* Rh(CNR)(carbodiimide) in $n$-heptane. (a) ps-TRIR and (b) ns-TRIR spectra in the $v(C N R)$ region at selected time delays. (c) Corresponding ps-TRIR kinetics: $\tau=430 \pm 30$ ps for the decay of 1 at $2083 \mathrm{~cm}^{-1}$ (black); and $\tau=360 \pm 60 \mathrm{ps}$ for the growth of 2 at $2108 \mathrm{~cm}^{-1}$ (red). (d) Corresponding ns-TRIR kinetics: $\tau=28( \pm 2) \mathrm{ns}$ for the decay of 2 at $2108 \mathrm{~cm}^{-1}$ (red); and $\tau=27( \pm 2) \mathrm{ns}$ for the growth of 3 at $2142 \mathrm{~cm}^{-1}$ (blue). 
Table 1: Frequencies for the species observed by $T R I R$ spectroscopy of $T p * R h(C N R)$ species in the $v(C N R)$ and $v(B-H)$ spectral region in $n$-heptane.

\begin{tabular}{lcc}
\hline Species & $v(\mathrm{CNR})$ region $\left(\mathrm{cm}^{-1}\right)$ & $v(\mathrm{~B}-\mathrm{H})\left(\mathrm{cm}^{-1}\right)$ \\
\hline $\mathrm{Tp} \mathrm{R}^{*} \mathrm{Rh}(\mathrm{CNR})$ (carbodiimide) & $2178^{a}$ & $2524^{a}$ \\
$\kappa^{3}-\eta^{1}$-alkane complex (1) & 2083 & 2520 \\
$\kappa^{2}-\eta^{2}$-alkane complex (2) & 2108 & 2485 \\
alkyl hydride (3) & 2142,2029 & 2518 \\
free carbodiimide & $2138^{b}$ & - \\
\hline
\end{tabular}

${ }^{a}$ lit. $2186 \mathrm{~cm}^{-1} / 2525 \mathrm{~cm}^{-1}(\mathrm{KBr}) .{ }^{9}$ lit. $2137 \mathrm{~cm}^{-1}\left(\mathrm{C}_{6} \mathrm{H}_{6}\right) .{ }^{9}$ This band is visible on the low frequency side of the band for $\mathbf{3}$ in Figure $\mathbf{2 b}$.
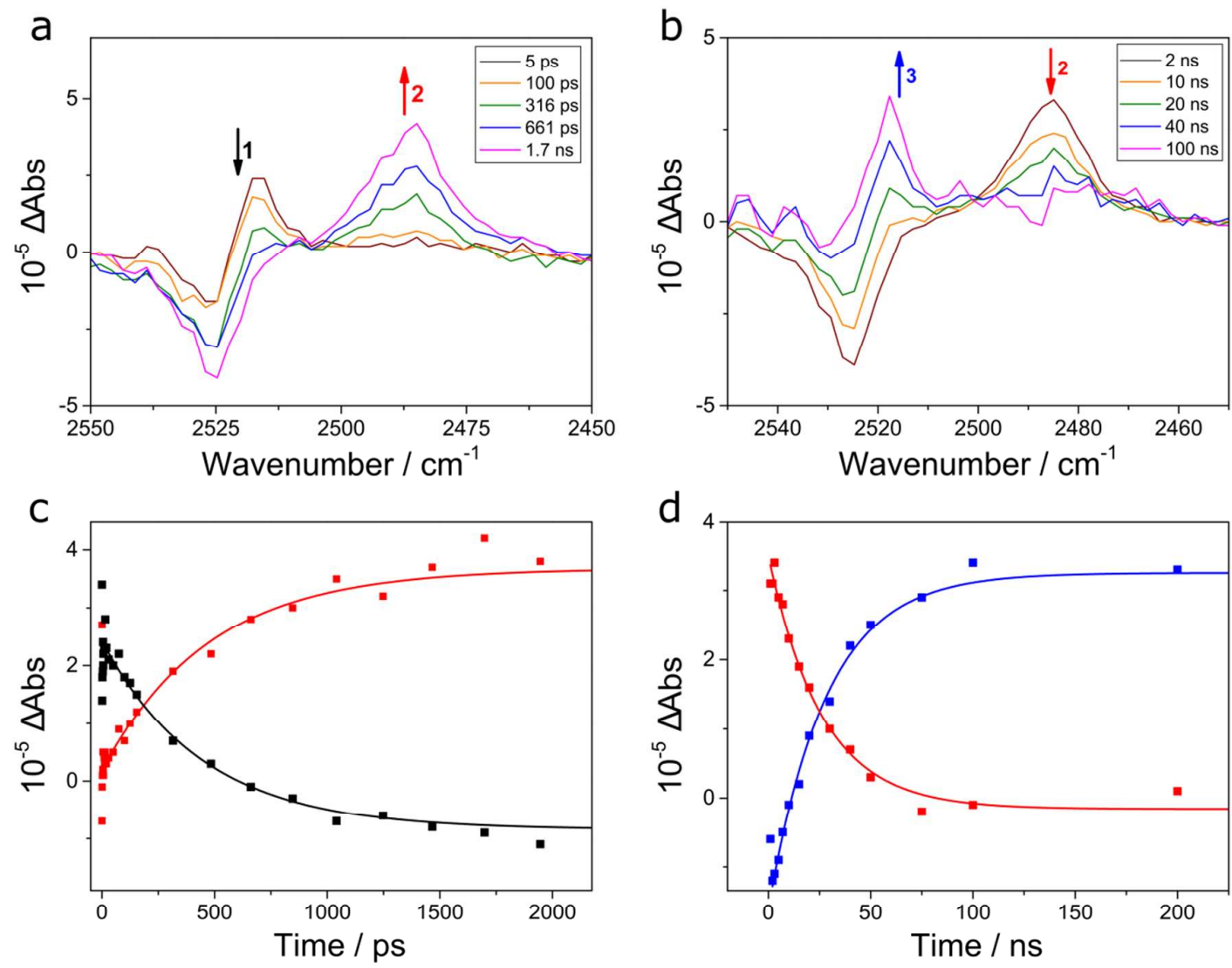

Figure 3: Photolysis (355 $\mathrm{nm}$ ) of $\mathrm{Tp} * \mathrm{Rh}(\mathrm{CNR})($ carbodiimide) in $n$-heptane. (a) ps-TRIR and (b) ns-TRIR spectra in the $v(B-H)$ region at selected time delays. (c) Corresponding ps-TRIR kinetics: $\tau=450 \pm 50 \mathrm{ps}$ for the decay of 1 at $2520 \mathrm{~cm}^{-1}$ (black); and $\tau=470 \pm 50 \mathrm{ps}$ for the growth of 2 at $2485 \mathrm{~cm}^{-1}$ (red). (d) Corresponding ns-TRIR kinetics: $\tau=26 \pm 3 \mathrm{~ns}$ for the decay of 2 at $2485 \mathrm{~cm}^{-1}$ (red); and $\tau=28 \pm 2 \mathrm{~ns}$ for the growth of 3 at $2518 \mathrm{~cm}^{-1}$ (blue). 
We have investigated the assignment of $\mathbf{1}$ and $\mathbf{2}$ further by repeating the ps-TRIR measurements in the B-H region. The $v(\mathrm{~B}-\mathrm{H})$ band is sensitive to mode of coordination $\left(\kappa^{2}\right.$ or $\kappa^{3}$ ) to the metal centre, see Table S1 in Supporting Information (SI). ${ }^{13}$ ps-TRIR spectra of the $v(\mathrm{~B}-\mathrm{H})$ spectral region of $\mathrm{Tp} * \mathrm{Rh}(\mathrm{CNR})$ (carbodiimide) after photolysis are shown in Figure 3(a). At a time delay of $1 \mathrm{ps}$, there is a clear parent bleach at $2524 \mathrm{~cm}^{-1}$ and a transient band at $2520 \mathrm{~cm}^{-1}$, which decays $[\tau=450( \pm 50) \mathrm{ps}]$ at the same rate $[470( \pm 50) \mathrm{ps}]$ as a new transient peak grows-in to lower wavenumber at $2485 \mathrm{~cm}^{-1}$. This behaviour mirrors the $v(\mathrm{CNR})$ TRIR experiments described above, Figure 2(a), and these bands in the $v(\mathrm{~B}-\mathrm{H})$ TRIR spectra are also assigned to the same intermediates, $\mathbf{1}$ and $\mathbf{2}$, respectively. Additionally, in the $v(B-H)$ TRIR spectra, the position of the peaks relative to the parent bleach is reversed when compared to the isocyanide spectral region (Figure 2(a)). For 1, the Tp* ligand is still in a $\kappa^{3}$-configuration, so the $v(B-H)$ is relatively unaffected relative to parent and its $v(B-H)$ frequency of $2520 \mathrm{~cm}^{-1}$ is diagnostic of $\kappa^{3}-\mathrm{Tp}^{*}$ coordination. ${ }^{13}$ Upon conversion of 1 to the $\kappa^{2}-\mathrm{Tp} *$ intermediate 2 , there should be a decrease of $v(\mathrm{~B}-\mathrm{H})$ upon conversion and the shift in $v(\mathrm{~B}-\mathrm{H})$ from 2520 to $2485 \mathrm{~cm}^{-1}$ is consistent with our assignment, ${ }^{13}$ and provides very strong evidence for the structure of the intermediates.

The photochemistry of $\mathrm{Tp} \mathrm{p}^{*} \mathrm{Rh}(\mathrm{CNR})$ (carbodiimide) was also investigated on the nanosecond timescale by TRIR spectroscopy in both the CNR and B-H region, Figures 2(b) and 3(b). The difference TRIR spectrum obtained $2 \mathrm{~ns}$ after photolysis (355) $\mathrm{nm}$ in $n$-heptane shows the same profile as the later time delays of the ps-TRIR experiment in both regions. In the CNR region a parent bleach is seen at $2178 \mathrm{~cm}^{-1}$, as well as the presence of intermediate 2 (a $\kappa^{2}$-alkane $\sigma$-complex) at $2108 \mathrm{~cm}^{-1} .2$ decays $[\tau=28( \pm 2) \mathrm{ns}]$ on the ns-timescale at the same rate $[27( \pm 2) \mathrm{ns}]$ as a new species, $\mathbf{3}$, grows in and this is observed at higher wavenumber overlapping with the free carbodiimide peak at $2138 \mathrm{~cm}^{-1}$. By analogy to the $\mathrm{C}-\mathrm{H}$ activation of $\mathrm{Cp}{ }^{\prime} \mathrm{Rh}(\mathrm{CO})_{2}{ }^{3,4}$ and $\mathrm{Tp}{ }^{\prime} \mathrm{Rh}(\mathrm{CO})_{2},{ }^{8} \mathbf{3}$ was assigned to a rhodium alkyl hydride. As $\mathrm{C}-\mathrm{H}$ 
activation occurs, the rhodium is oxidised from +1 to +3 , resulting in a decrease in electron donation from the metal to the CNR antibonding orbitals. Therefore, the CNR bonding is strengthened and there is an associated increase in wavenumber of the stretching vibration. Concurrently with the formation of this new isocyanide peak, the rise of a small peak to lower wavenumber is observed at $2029 \mathrm{~cm}^{-1}$. This peak is assigned to the metal-hydride stretch of the alkyl hydride 3 and consistent with the low oscillator strength of the v(M-H) band compared to $\mathrm{CO}$ or $\mathrm{CN}$ stretches. ${ }^{14}$ The similar timescale to the $\mathrm{C}-\mathrm{H}$ activation of the more widely studied $\mathrm{Tp} \mathrm{Rh}^{\mathrm{R}}(\mathrm{CO})_{2}{ }^{8}$ and $\mathrm{Cp} \mathrm{p}^{\mathrm{R}} \mathrm{R}(\mathrm{CO})_{2}{ }^{3,4}$ also indicates that the conversion of $\mathbf{2}$ to 3 corresponds to that of an alkane $\sigma$-complex to an alkyl hydride.

We also observed similar processes in the B-H region. The transient peak $\mathbf{2}$ decays over the course of the time delays displayed in Figure 3(b) and there is a concurrent growth at 2518 $\mathrm{cm}^{-1}$, which was assigned to the alkyl hydride, 3 . The $v(\mathrm{~B}-\mathrm{H})$ frequency of $\mathbf{3}$ is indicative of the Tp* ligand in a $\kappa^{3}$ configuration. ${ }^{13}$ Furthermore, the position of $\mathbf{3}$ relative to the parent fits with an alkyl hydride in a similar $\kappa^{3}$ environment to the parent. As the alkane is C-H activated the pyrazolyl arm is proposed to rechelate resulting in a $\kappa^{3}$-configuration and $\mathbf{3}$ having a similar $v(B-H)$ frequency to the parent. Figure 3(d) shows kinetic traces obtained from the ns-TRIR spectra in the $v(B-H)$ region, and the traces for the decay of $\mathbf{2}$ and formation of $\mathbf{3}$ match within error, with measured lifetimes of $26( \pm 3)$ and $29( \pm 2 \mathrm{~ns})$, respectively.

\section{Density Functional Theory (DFT) calculations on the activation of $n$-heptane. DFT}

calculations are performed, to gain insights into the different intermediates observed by TRIR spectroscopy and to help confirm the assignment of each peak to a specific intermediate (see Experimental section for detailed computational methodology). To decrease the computational time, $\mathrm{Tp}^{*}$ was replaced by $\mathrm{Tp}$ as in previous investigations ${ }^{8,12}$ and $\mathrm{CNMe}$ was used as CNR; these change are not thought to dramatically affect the electronic structure or the relative accuracy. The optimized geometries are shown in Figure 4 with selected 
distances in Table 2. The $\kappa^{3}-\eta^{1}$-alkane complex (1) with the alkane weakly bound in an $\eta^{1}$ fashion, analogous to previous calculations on the closely related $\mathrm{Tp}$ ' $\mathrm{Rh}(\mathrm{CO})($ alkane) complexes, ${ }^{8}$ has the alkane relatively far from the metal with a Rh-H1 distance of $3.11 \AA$ and an almost unaffected $\mathrm{C} 1-\mathrm{H} 1$ bond $(1.10 \AA)$. The $\kappa^{3}$-Tp ligand has three nearly equal Rh-N1 distances, 2.14 to $2.23 \AA$. In the $\kappa^{2}-\eta^{2}$-alkane complex (2), the alkane is much closer to the metal, the Rh-H1 decreases to $1.85 \AA$, and $\mathrm{C} 1-\mathrm{H} 1$ bond elongates to $1.14 \AA$. Note that the calculated Rh-C bond length $(2.40 \AA)$ in 2 and those $(2.386-2.465 \AA)$ in the $c$-alkane $\sigma$ complexes in the following section resemble those in rhodium $\sigma$-alkane complexes that have been crystallographically characterized by Macgregor, Weller and their coworkers ${ }^{15 b-e}$ following the first NMR characterization of a $\mathrm{Rh}(\mathrm{I}) \sigma$-methane complex by Bernskoetter and coworkers $^{15 \mathrm{a}}$. The alkane's strong binding to the metal is accompanied by the Tp ligand changing to a $\kappa^{2}$-coordination, as shown in Figure 4, with the unbound nitrogen N1 $3.58 \AA$ away from the metal and N2 and N3 both closer to the metal than in $\mathbf{1}$. Thus, $\mathbf{2}$ is the square planar structure expected for a $d^{8}$ metal without strong $\pi$ acceptors. After oxidative addition of the alkane, the Tp returns to a $\kappa^{3}$-configuration in the alkyl hydride (3), as expected. All these observations correspond with those for the similar Tp'Rh(CO)(alkane) systems. ${ }^{8}$ 

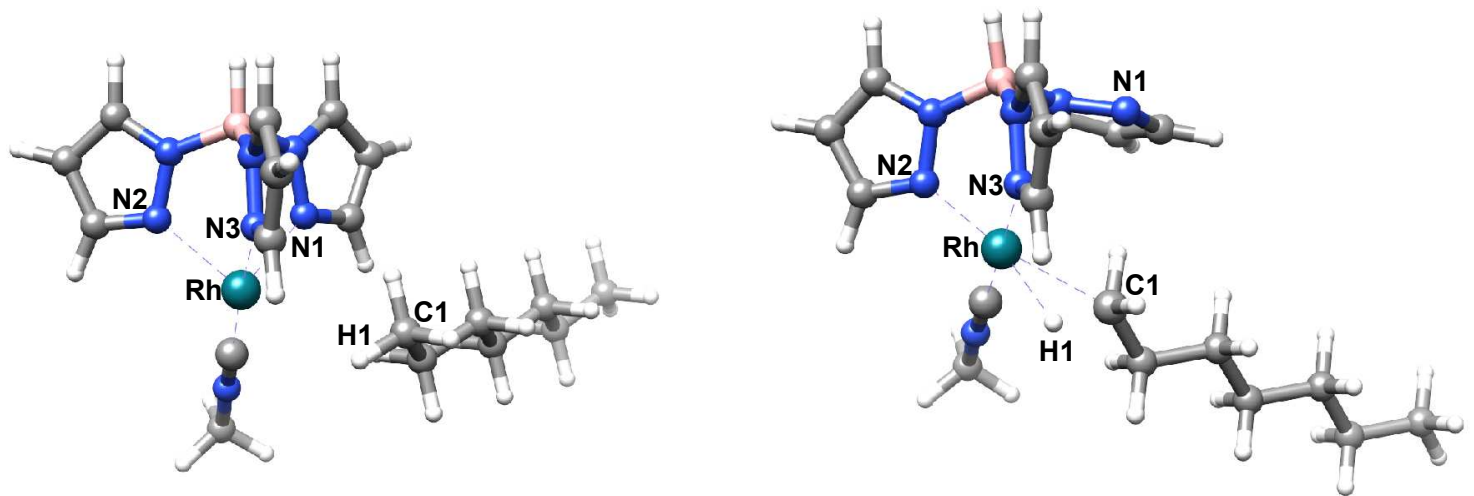

${ }^{3} k^{3}-\eta^{1}$-alkane complex (1)

${ }^{1} k^{2}-\eta^{2}$-alkane complex (2)

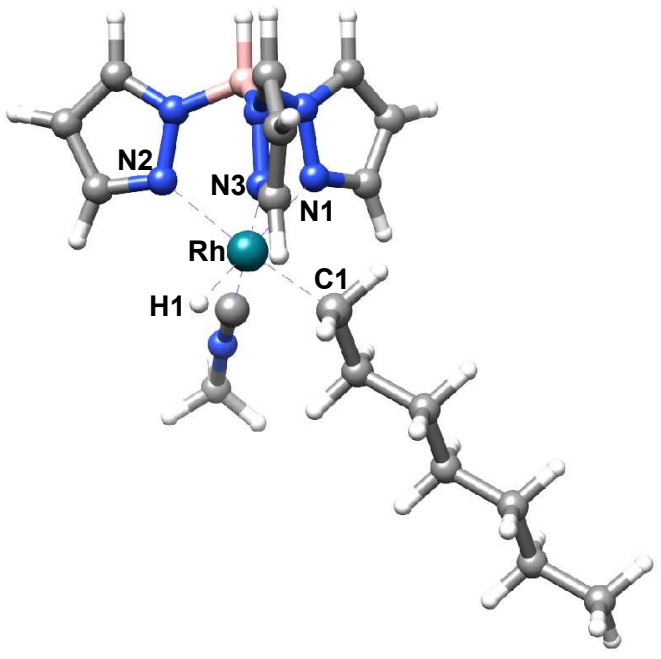

${ }^{1} k^{3}$-alkyl hydride (3)

Figure 4: DFT calculated optimized geometries of the $\kappa^{3}-\eta^{1}$-alkane complex $\left(1\right.$, triplet), the $\kappa^{2}$ $\eta^{2}$-alkane complex $\left(2\right.$, singlet) and the $\boldsymbol{\kappa}^{3}$-alkyl hydride $(3$, singlet) in $n$-heptane.

Table 2: Selected bond lengths from the optimized geometries of the different intermediates calculated with DFT. The specific atoms are denoted in Figure 4.

\begin{tabular}{ccccccc}
\hline \multirow{2}{*}{ Calculated Species } & \multicolumn{7}{c}{ Bond Lengths $(\AA)$} \\
\cline { 2 - 7 } & Rh-H1 & Rh-C1 & C1-H1 & Rh-N1 & Rh-N2 & Rh-N3 \\
\hline$\kappa^{3}-\eta^{1}$-alkane complex (1) & 3.11 & 3.50 & 1.10 & 2.22 & 2.23 & 2.14 \\
$\kappa^{2}-\eta^{2}$-alkane complex (2) & 1.85 & 2.40 & 1.14 & 3.58 & 2.02 & 2.07 \\
alkyl hydride (3) & 1.55 & 2.06 & 2.54 & 2.18 & 2.16 & 2.08 \\
\hline
\end{tabular}


Vibrational frequencies were also computed for these intermediates, Table 3. Important information can be obtained from their value relative to the parent frequencies, which were also computed. Examination of the calculated $v(\mathrm{CNR})$ frequencies in Table 3 indicates the following order: parent $>\mathbf{3}>\mathbf{2}>\mathbf{1}$. This replicates the trend in wavenumber observed by TRIR spectroscopy.

Table 3: DFT calculated and experimentally observed frequencies in the $v(C N R)$ and $v(B H)$ spectral regions for the different $\mathrm{C}-\mathrm{H}$ activation intermediates.

\begin{tabular}{ccccc}
\hline \multirow{2}{*}{ Calculated Species } & \multicolumn{2}{c}{$v(\mathrm{CNR})[\mathrm{Rh}-\mathrm{H}]\left(\mathrm{cm}^{-1}\right)$} & \multicolumn{2}{c}{$v(\mathrm{~B}-\mathrm{H})\left(\mathrm{cm}^{-1}\right)$} \\
\cline { 2 - 5 } & Calc. $^{a}$ & Exp. & Calc. $^{b}$ & Exp. \\
\hline Tp'Rh(CNR)(carbodiimide) & 2163 & 2177 & 2524 & 2523 \\
$\begin{array}{c}\text { (parent) } \\
\kappa^{3}-\eta^{1} \text {-alkane complex (1) }\end{array}$ & 2090 & 2083 & 2510 & 2514 \\
$\kappa^{2}-\eta^{2}$-alkane complex (2) & 2108 & 2108 & 2480 & 2483 \\
alkyl hydride (3) & $2146\left[2069^{c}\right]$ & $2142[2029]$ & 2518 & 2518 \\
\hline${ }^{a, b}$ Scaling factors of 0.928 and 0.970, respectively (from calculated to experimental values, see Table \\
S3 in SI for the scaling procedure). ${ }^{c}$ Scaling factor of 0.928 is uncalibrated for Rh-H frequency.
\end{tabular}

The frequencies obtained from DFT calculations add further support to the assignments of $\mathbf{1}$, 2 and 3 to a $\kappa^{3}-\eta^{1}$-alkane complex, a $\kappa^{2}-\eta^{2}$-alkane complex and an alkyl hydride, respectively. Furthermore, calculations predict a weak Rh-H stretch at $2069 \mathrm{~cm}^{-1}$, which corresponds to the ns-TRIR spectra described in Figure 2(b), where a small peak at $2029 \mathrm{~cm}^{-1}$ appears to grow in concurrently with the $v(\mathrm{CNR})$ of $\mathbf{3}$ at $2142 \mathrm{~cm}^{-1}$.

Frequencies calculated in the $\mathrm{v}(\mathrm{B}-\mathrm{H})$ region for the different intermediates of $\mathrm{C}-\mathrm{H}$ activation also correlate well with the peaks observed by TRIR spectroscopy. Upon conversion of $\mathbf{1}$ to 2, a decrease of $30 \mathrm{~cm}^{-1}$ was predicted by the calculations, corresponding to a downshift of 31 $\mathrm{cm}^{-1}$ observed by TRIR spectroscopy. The C-H activation of $\mathbf{2}$ to $\mathbf{3}$ leads to an increase in the predicted frequency of $38 \mathrm{~cm}^{-1}$, resulting in a peak on the lower frequency shoulder of the parent. The matching of these predicted trends and relative positions to the parent frequency 
with those observed by TRIR spectroscopy provide further evidence for the proposed C-H activation mechanism.

In summary, like $\mathrm{Tp}^{\prime} \mathrm{Rh}(\mathrm{CO})$, dechelation of one arm of the $\mathrm{Tp}$ ' occurs to form the $\kappa^{2}-$ Tp'(CNR)(n-heptane) complex, which then activates the C-H bond with synchronization of the rechelation of the Tp'. However, there are clearly additional processes occurring in the early times of the spectra that are discussed below.

Early time observations in the TRIR spectra. At early times in both the CNR and B-H regions, there are several other features. An intense band to lower frequency of the parent remains constant on the ps-timescale at $2138 \mathrm{~cm}^{-1}$ and is consistent with production of free carbodiimide ligand after it is photo-ejected from the rhodium by comparison to the literature. ${ }^{9}$ Ejection of isonitrile from these $d^{6} \mathrm{Rh}(\mathrm{III})$ complexes has not been observed. The carbodiimide complex takes on Rh(III) character as clearly seen in it's X-ray structure: octahedral, $d^{6}$, low spin. ${ }^{9 \mathrm{~b}}$ It has a high quantum yield for carbodiimide photodissociation $(\sim 1.0)$, which is several orders of magnitude higher than for isonitrile photodissociation from $\mathrm{Tp}$ 'Rh(CNR $)_{2}{ }^{9}$ There are several other bands that are either present at 1 ps or grow-in over the first $10-20$ ps. These are tentatively assigned to in-cage re-coordination of the photoejected carbodiimide ligand to the rhodium to form $\eta^{2}$-arene complexes or to reform the parent complex.

The TRIR spectra at early time around the parent $v(\mathrm{CNR})$ band is complicated and there is some spectroscopic evidence for a transient with a band which is present as a small shoulder at $2156 \mathrm{~cm}^{-1}$ and this band decays $[6( \pm 1) \mathrm{ps}]$ at the same rate as the apparent parent recovery at $2178 \mathrm{~cm}^{-1}$, which can be fitted to a biexponential growth $[5( \pm 1)$ and $50( \pm 10) \mathrm{ps}]$. Therefore, the band at $2156 \mathrm{~cm}^{-1}$ is tentatively assigned to a $\kappa^{2}$-parent complex with one dechelated pyrazolyl arm (see DFT results below) formed after photoexcitation that 
rearranges to reform the parent. As stated above, the partial reformation of the parent can be fitted to a biexponential with the slower part occurring with a 50 ps process and we also observe the growth of a shoulder at $2130 \mathrm{~cm}^{-1}$, which occurs on a similar timescale $[50( \pm 10)$ ps]. The slower processes can be assigned to the re-coordination of the free ligand to the $\kappa^{2}$ $\mathrm{Tp} * \mathrm{Rh}(\mathrm{CNR})$ residue after the photolysis, where the $\kappa^{2}-\eta^{2}$-arene complex are generated. The migration of the $\mathrm{Rh}$ about the aryl ring and the re-chelation of the $\kappa^{2}-\eta^{2}$-arene complex to the $\kappa^{3}-\eta^{2}$-arene complex give rise to the two growths on the $50 \mathrm{ps}$ timescale, where the calculated bands (see DFT results below) agree well with the spectra.

DFT calculations on early time observations. Figure 5 summarizes the results of the DFT calculations that were performed to understand these early-time spectral features; in addition to the structure and the relative energy, Figure 5 displays the $v(\mathrm{CNR})$ values as 'predicted(measured )'. The parent complex, $\kappa^{3}-\mathrm{Tp}$ ' $\mathrm{Rh}(\mathrm{CNR})($ carbodiimide), is excited to the excited state, [parent]*, which mainly decays to the longer-lived unsaturated triplet $\kappa^{3}-\mathrm{Tp}$ 'Rh(CNR)(alkane) fragment after vibrational cooling, and this fragment will subsequently proceed to activate the alkane. In addition, [parent]* may decay by two distinct minor pathways: on the one hand, it can render a stable $\kappa^{2}$-parent with a $v(\mathrm{CNMe})$ of 2151 $\mathrm{cm}^{-1}$, which agrees well with the observed band of $2156 \mathrm{~cm}^{-1}$ in the TRIR spectra. The dechelated pyrazolyl arm of this $\kappa^{2}$-parent rechelates via a small rotation barrier of 1.7 $\mathrm{kcal} / \mathrm{mol}$ to render the $\kappa^{3}$-parent, here this shallow barrier corresponds to a estimated lifetime of $3 \mathrm{ps}$, which fits well with the observed fast recovery of parent at $2178 \mathrm{~cm}^{-1}$ band on a timescale of $[6( \pm 1) \mathrm{ps}]$ in spectra.

On the other hand, ejection of the carbodiimide ligand from the [parent]* could also generate the $\kappa^{2}-\mathrm{Tp}$ 'Rh(CNR) residue in the singlet state, where the adjacent free ligand can recoordinate to form the $\kappa^{2}-1,2-\eta^{2}$-arene complex. Through a rechelation TS with a barrier of $2.9 \mathrm{kcal} / \mathrm{mol}$, this arene complex can rearrange to generate the corresponding more stable $\kappa^{3}$ - 
$1,2-\eta^{2}$-arene complex that has a calculated band of $2150 \mathrm{~cm}^{-1}$, which fits reasonably well with the observed recovery at $2178 \mathrm{~cm}^{-1}$ in spectra, as its calculated $v(\mathrm{CNR})$ is similar to the calculated $v(\mathrm{CNR})$ of the parent, $2163 \mathrm{~cm}^{-1}$. Further, this initial arene complex can undergo an arene migration with a barrier of $2.4 \mathrm{kcal} / \mathrm{mol}$ to form a more stable $\kappa^{2}-2,3-\eta^{2}$-arene complex that has a calculated band of $2119 \mathrm{~cm}^{-1}$, corresponding to the growth of a shoulder at $2130 \mathrm{~cm}^{-1}$. Note that this $\kappa^{2}-2,3-\eta^{2}$-arene complex does not rearrange to the $\kappa^{3}$ conformation due to steric issues from strong interaction between the benzene ring and the dechelated pyrazol arm that barricade the dechelated pyrazol arm from rechelating with the $\mathrm{Rh}$, trapping this $\kappa^{2}-2,3-\eta^{2}$-arene complex in $\kappa^{2}$ conformation and validating the spectral observation of no decay in both growths. In contrast, the existence of a hydrogen bond $(\mathrm{H} \cdots \mathrm{N}$ bond length: $2.35 \AA$, indicated by colour pink in Figure 6) in the $\kappa^{2}-1,2-\eta^{2}$-arene complex between the hydrogen in the chelated pyrazol arm and the nitrogen in the carbodiimide restrains the carbodiimide and keeps it from blocking the dechelated pyrazol arm from rechelation. Furthermore, these $1,2-\eta^{2}$-arene complexes are quite stable and will not evolve further in the short time scale; however, in longer times they may undergo aryl $\mathrm{C}-\mathrm{H}$ activation of the phenyl ring on the carbodiimide ligand on the ns timescale, the products of which have also been observed by NMR experiments in previous studies. ${ }^{9,10}$ 


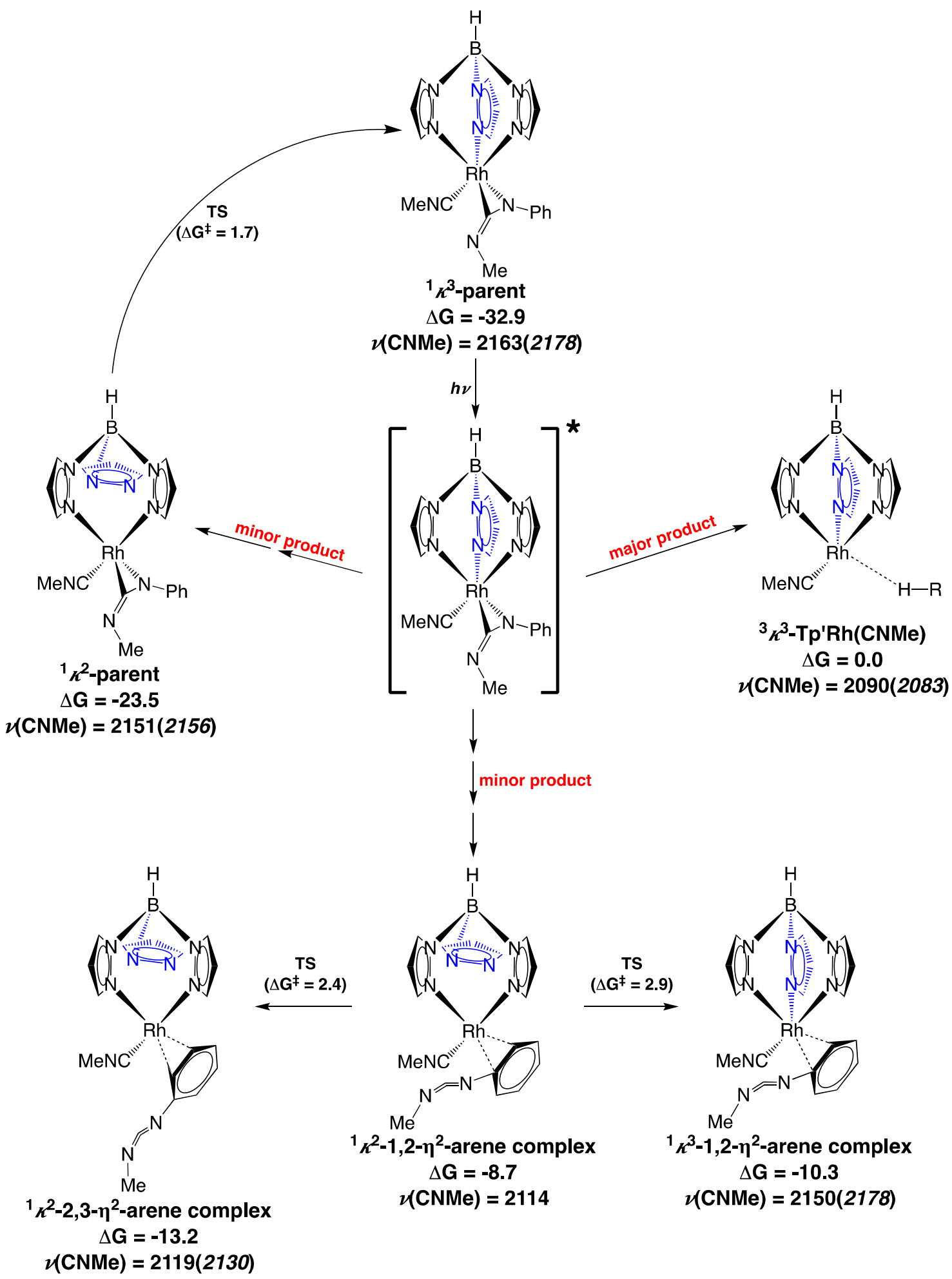

Figure 5: DFT calculations on the proposed species seen in the early stages after photolysis. $v(C N R)$ frequencies presented as predicted (measured). 


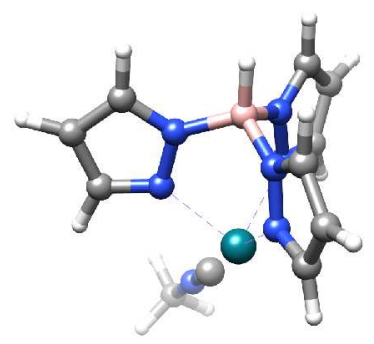

${ }^{3} \kappa^{3}-\mathrm{Tp} \mathrm{Rh}^{\mathrm{CNNMe})}$ ( ${ }^{1} \kappa^{3}$-parent)

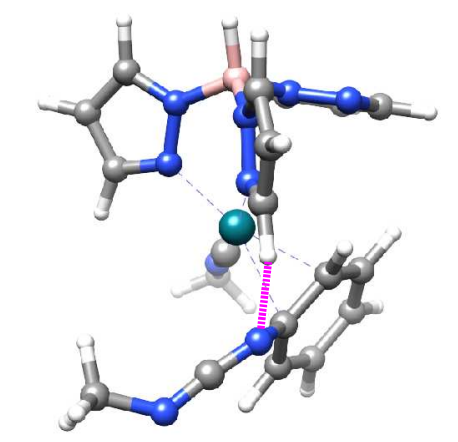

$1 k^{2}-1,2-\eta^{2}$-arene complex

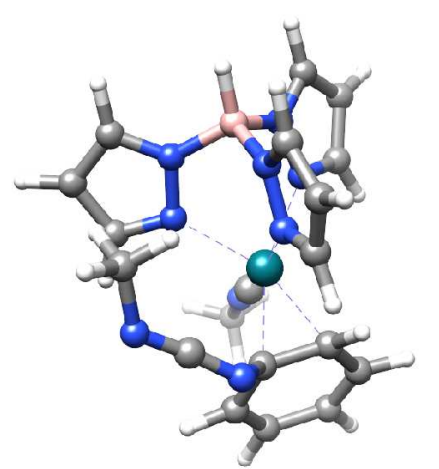

$1 \kappa^{3}-1,2-\eta^{2}$-arene complex

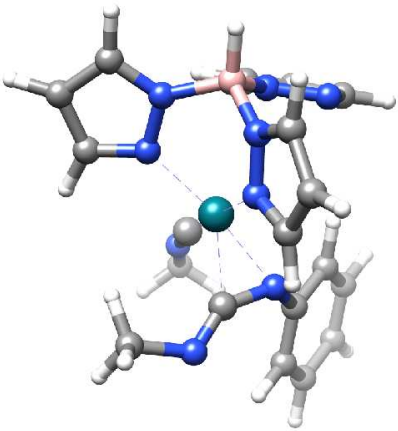

${ }^{1} \kappa^{2}$-parent

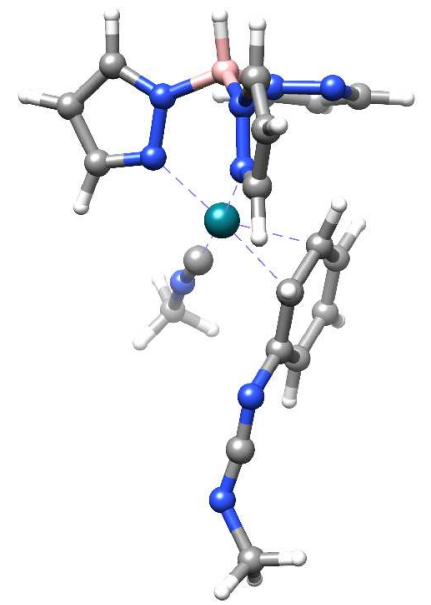

\section{$1 \kappa^{2}-2,3-\eta^{2}$-arene complex}

Figure 6: Optimized molecular structures of the parent $\operatorname{TpRh}(\mathrm{CNMe})$ (carbodiimide) and other species generated in the early stage.

Table 4: Relative energies $(\mathrm{kcal} / \mathrm{mol})$ and frequencies $\left(\mathrm{cm}^{-1}\right)$ of DFT calculated parent $\operatorname{TpRh}(\mathrm{CNMe})$ (carbodiimide), TpRh(CNMe) residue, and $\eta^{2}$-arene complexes in $\boldsymbol{\kappa}^{3}$ and $\boldsymbol{\kappa}^{2}$ conformations, respectively, in the early stage after photolysis. Structures are shown in Figures 5 and 6.

\begin{tabular}{cccc}
\hline Calculated Species & $\Delta \mathrm{G}$ & \multicolumn{2}{c}{ Wavenumber $\left(\mathrm{cm}^{-1}\right)$} \\
\cline { 3 - 4 } & & $\boldsymbol{v}(\mathbf{C N M e})$ & $\boldsymbol{v}(\mathbf{B}-\mathbf{H})$ \\
\hline $\mathrm{TpRh}(\mathrm{CNMe})$ (carbodiimide) $\left({ }^{1} \kappa^{3}\right.$-parent) & -32.9 & 2163 & 2525 \\
${ }^{1} \kappa^{2}$-parent & -23.5 & 2151 & 2500 \\
${ }^{3} \kappa^{3}-\mathrm{TpRh}(\mathrm{CNMe})$ & ${ }^{a} 0.0$ & 2090 & 2509 \\
${ }^{1} \kappa^{3}-1,2-\eta^{2}$-arene complex & -10.3 & 2150 & 2515 \\
${ }^{1} \kappa^{2}-1,2-\eta^{2}$-arene complex & -8.7 & 2114 & 2477 \\
${ }^{1} \kappa^{2}-2,3-\eta^{2}$-arene complex & -13.2 & 2119 & 2477 \\
\hline
\end{tabular}

${ }^{a}$ Total energies of the triplet $\kappa^{3}-\mathrm{TpRh}(\mathrm{CNMe})$ residue and free carbodiimide are set as zero. 
Although one might expect a high degree of similarity in the photo-initiated $\mathrm{C}-\mathrm{H}$ activation reaction between $\mathrm{Tp}^{\prime} \mathrm{Rh}(\mathrm{CO})_{2}$ and the $\mathrm{Tp}$ ' $\mathrm{Rh}(\mathrm{CNR})$ (carbodiimide), there are significant differences in the early-time dynamics from additional reactions arising from the slow ejection of the heavier carbodiimide that results in the formation of other species especially $\eta^{2}$-arene $\pi$-complexes. In spite of these interesting differences, the major reaction paths of both involve ligand loss, $\sigma$-alkane complex formation and $\mathrm{C}$-H activation, but with significant differences in the rates as described below for the cycloalkanes.

\section{Rates of C-H activation of Cyclic Alkanes by Tp'Rh(CNR)}

We have previously investigated the effect of changing the nature of the alkane on the reactivity of $\mathrm{Cp}^{\prime} \mathrm{Rh}(\mathrm{CO})(\text { alkane })^{3-5}$ and $\mathrm{Tp}{ }^{\prime} \mathrm{Rh}(\mathrm{CO})(\text { alkane })^{8}$ and as stated above different factors affect the rate depending upon the nature of the complex and the alkane.

The $\mathrm{C}$-H activation lifetimes of four cycloalkanes ( $c$-pentane, $c$-hexane, $c$-heptane and c-octane) with the $\mathrm{Tp} * \mathrm{Rh}(\mathrm{CNR})$ fragment was determined by looking at the growth of $\mathbf{3}$. Normalised kinetic traces for the $\mathrm{C}-\mathrm{H}$ activation reactions of the different cycloalkanes, Figure 7, show a significant increase in the lifetime as the size of the cycloalkane increases. The largest cycloalkane studied in this work, $c$-octane, has the longest lifetime of $1570( \pm 70)$ ns and $c$-pentane has the shortest at $220( \pm 10)$ ns. Furthermore, the rates for $c$-pentane and $c$-hexane are similar, as are those of $c$-heptane and $c$-octane. Thus, a step-like lifetime trend is observed, Figure 8. Similar step-like trends with a dramatic change in lifetime between $c$ hexane and $c$-heptane have been reported for the $\mathrm{CpRh}(\mathrm{CO})$ and $\mathrm{Cp} * \mathrm{Rh}(\mathrm{CO})$ fragments ${ }^{5}$ and the latter is compared with $\mathrm{Tp} * \mathrm{Rh}(\mathrm{CNR})$ in Figure 8. 


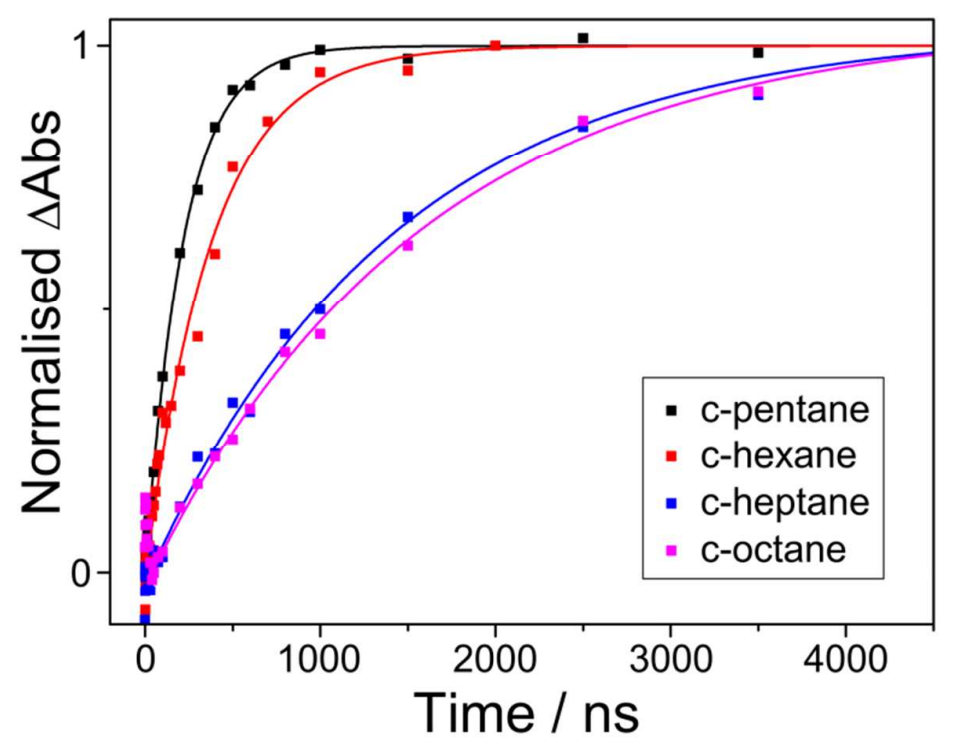

Figure 7: Kinetic traces and mono-exponential fits for the room temperature $\mathrm{C}-\mathrm{H}$ activation of cycloalkanes by the $T p * R h(C N R)$ fragment.

The similarity of the lifetime trend for the $\mathrm{Tp} * \mathrm{Rh}(\mathrm{CNR})$ fragment to that of the $\mathrm{Cp} * \mathrm{Rh}(\mathrm{CO})$ fragment with the same step-like feature observed, demonstrates the inherent control that the nature of the alkane has on the relative rate of $\mathrm{C}-\mathrm{H}$ activation. However, the absolute lifetimes for the $\mathrm{Tp} \mathrm{p}^{*} \mathrm{Rh}(\mathrm{CNR})$ fragment are considerably longer than their $\mathrm{Cp} * \mathrm{Rh}(\mathrm{CO})$ counterparts. These lifetimes show that although the specific alkane exerts influence on the relative rate when compared to other alkanes, the metal fragment initiating the $\mathrm{C}-\mathrm{H}$ activation still has significant control as well. 


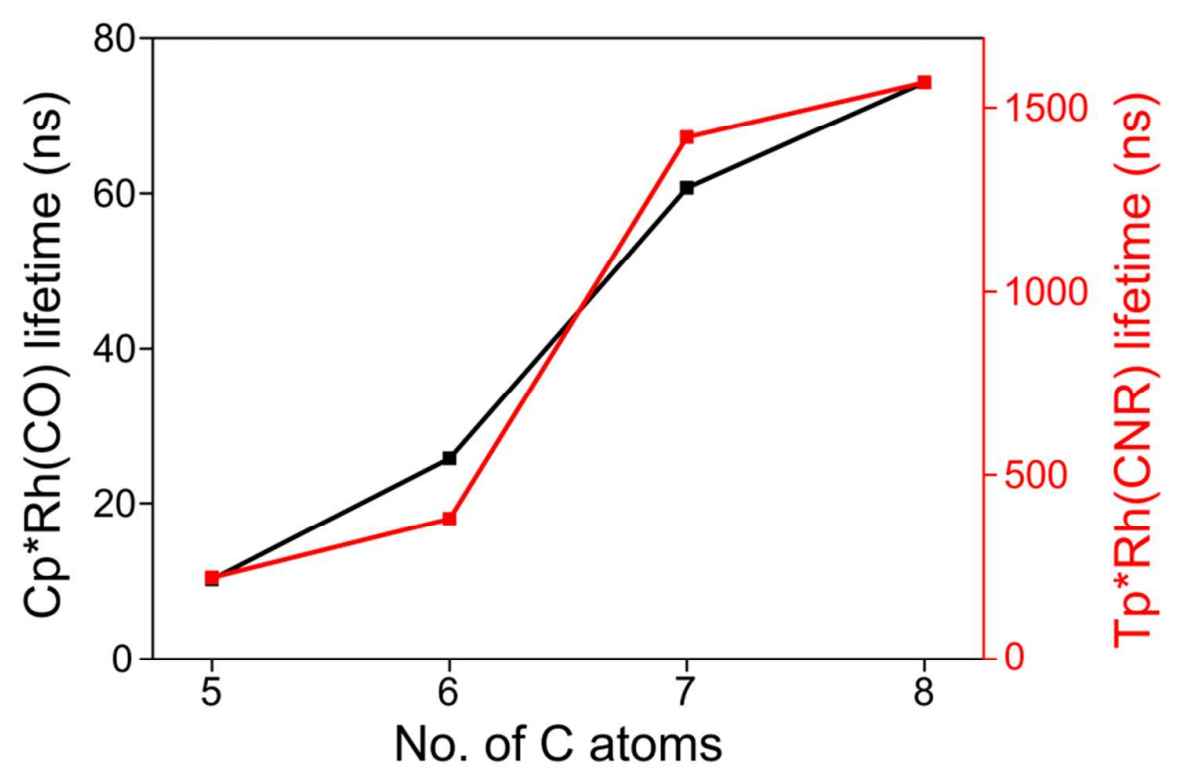
Figure 8: Scaled lifetime trends for the $\mathrm{C}-\mathrm{H}$ activation of cycloalkanes by $\mathrm{Tp} * \mathrm{Rh}(\mathrm{CNR})$ (red)
and $\mathrm{Cp} * \operatorname{Rh}(\mathrm{CO})^{5}$ (black).

Lifetimes of the $\mathrm{C}-\mathrm{H}$ activation of cycloalkanes by the $\mathrm{Tp} * \mathrm{Rh}(\mathrm{CO})$ fragment were also measured at room temperature and are summarised in Table $\mathbf{5}$ along with the lifetimes for the $\mathrm{Tp} * \mathrm{Rh}(\mathrm{CNR})$ fragment, and those previously reported for the $\mathrm{Cp}$ ' $\mathrm{Rh}(\mathrm{CO})$ fragments. Although the lifetimes measured for $c$-pentane and $c$-hexane with the $\mathrm{Tp} * \mathrm{Rh}(\mathrm{CNR})$ fragment are similar to those with the $\mathrm{Tp} * \mathrm{Rh}(\mathrm{CO})$ fragment, the lifetimes for $c$-heptane and $c$-octane are much longer with the $\mathrm{Tp} * \mathrm{Rh}(\mathrm{CNR})$ fragment. This observation may be related to the appearance of significant steric problems between CNR and a larger cycloalkane.

Using these values, lifetime trends for all four rhodium fragments were normalised and plotted together for comparison, Figure 9. Upon examination of the normalised lifetime trends, those of the $\mathrm{Cp} * \mathrm{Rh}(\mathrm{CO})$ and $\mathrm{Tp} * \mathrm{Rh}(\mathrm{CNR})$ fragments are very similar in nature, although there is more exaggerated step between the $c$-hexane and $c$-heptane lifetimes for the $\mathrm{Tp} * \mathrm{Rh}(\mathrm{CNR})$ fragment. In a similar manner to all of the other rhodium fragments, $\mathrm{Tp} * \mathrm{Rh}(\mathrm{CO})$ also exhibits a step-like $\mathrm{C}-\mathrm{H}$ activation lifetime trend with a large increase in 
lifetime between $c$-hexane and $c$-heptane, again showing the influence that the nature of the alkane has on the relative rate of $\mathrm{C}-\mathrm{H}$ activation. However, there are considerable differences between the fragments. $\mathrm{CpRh}(\mathrm{CO})$ shows a relatively linear relationship, particularly between $c$-hexane and $c$-octane, whereas $\mathrm{Cp} * \mathrm{Rh}(\mathrm{CO})$ and $\mathrm{Tp}$ ' $\mathrm{Rh}(\mathrm{CNR})$ have very pronounced steps in their trends.

Table 5: Room temperature lifetimes for the $\mathrm{C}-\mathrm{H}$ activation of cycloalkanes by the different rhodium fragments studied: $\mathrm{CpRh}(\mathrm{CO}) ; \mathrm{Cp} * \mathrm{Rh}(\mathrm{CO})$; $\mathrm{Tp} * \mathrm{Rh}(\mathrm{CNR})$; and $\mathrm{Tp} * \mathrm{Rh}(\mathrm{CO})$.

\begin{tabular}{ccccc}
\hline & \multicolumn{4}{c}{$\mathbf{C - H}$ activation lifetime (ns) } \\
\cline { 2 - 5 } & $\mathbf{C p R h ( C O ) ) ^ { a }}$ & $\mathbf{C p}^{*} \mathbf{R h}(\mathbf{C O})^{a}$ & $\mathbf{T p}^{*} \mathbf{R h}(\mathbf{C N R})$ & $\mathbf{T p}^{*} \mathbf{R h}(\mathbf{C O})$ \\
\hline $\boldsymbol{c}$-pentane & $5.9( \pm 0.2)$ & $10.2( \pm 0.8)$ & $220( \pm 10)$ & $230( \pm 10)$ \\
$\boldsymbol{c}$-hexane & $8.6( \pm 0.3)$ & $25.8( \pm 2.0)$ & $380( \pm 40)$ & $280( \pm 15)$ \\
$\boldsymbol{c}$-heptane & $22.7( \pm 0.7)$ & $60.7( \pm 2.4)$ & $1415( \pm 50)$ & $550( \pm 45)$ \\
$\boldsymbol{c}$-octane & $31.7( \pm 0.9)$ & $74.3( \pm 4.0)$ & $1570( \pm 70)$ & $640 *( \pm 60)$ \\
${ }^{a}$ from Ref. ${ }^{5} *$ Unidentified peak due to suspected $c$-octene complex from impurity or \\
side-reaction was present, but lifetime was obtained from unobscured alkyl hydride peak.
\end{tabular}

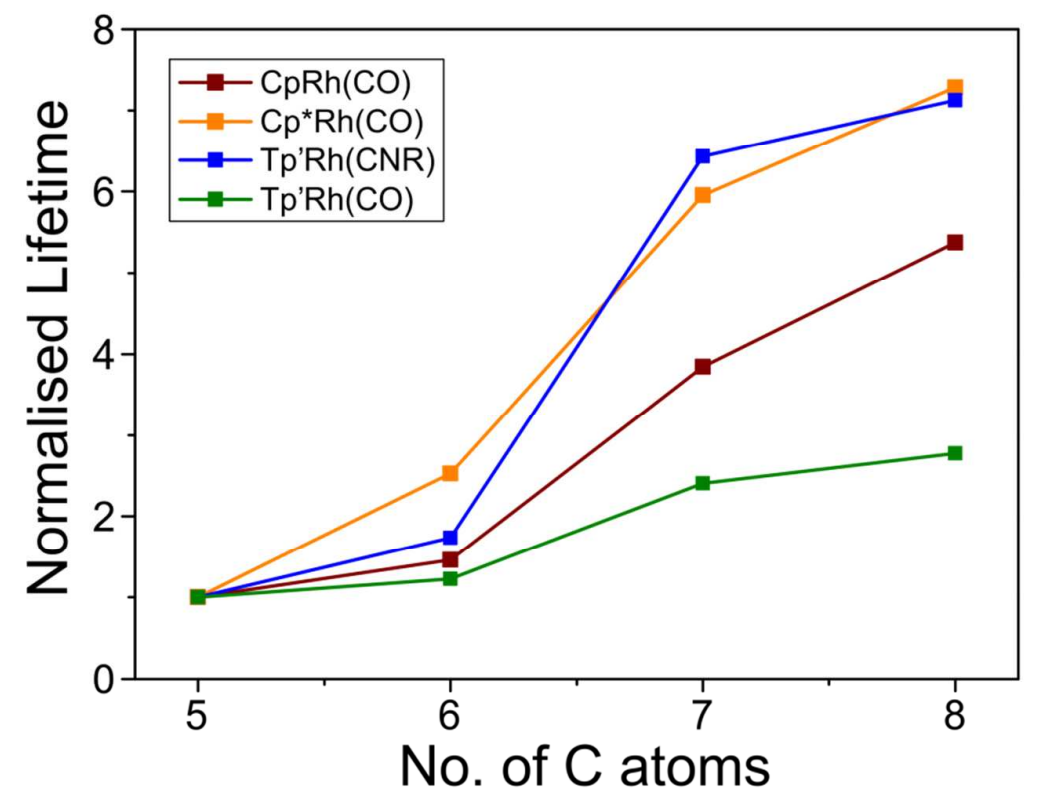


Figure 9: Lifetime trends for the $\mathrm{CpRh}(\mathrm{CO})^{5}$ (red), $\mathrm{Cp} * \mathrm{Rh}(\mathrm{CO})^{5}$ (orange), $\mathrm{Tp}{ }^{*} \mathrm{Rh}(\mathrm{CNR})$ (blue) and $\mathrm{Tp} * \mathrm{Rh}(\mathrm{CO})$ (green) fragments with the cycloalkanes (c-pentane to $c$-octane). All of the lifetimes with $c$-pentane were normalised to 1 .

Although the $\mathrm{Tp}^{*}$ complexes are only differentiated by a $\mathrm{CO}$ or a $\mathrm{CNR}$ ligand, this has a large effect on their lifetime trends. For $c$-pentane, Tp'Rh(CO) and Tp'Rh(CNR) have similar lifetimes of $230( \pm 10)$ and $220( \pm 10)$ ns, respectively, but for the larger $c$-octane, there is a large difference between their lifetimes of $640( \pm 60)$ and $1570( \pm 70)$ ns, respectively. These changes are proposed to be due to the sterics of the two fragments. Tp'Rh(CNR) is much more sterically crowded than the analogous $\mathrm{Tp}$ 'Rh(CO) due to the bulky isocyanide neopentyl group. This steric difference may hinder the rechelation of the Tp' arm, which has been proposed to be crucially important for $\mathrm{C}-\mathrm{H}$ activation, ${ }^{8}$ or simply make the transition state for the larger cycloalkanes more crowded. All of these differences between the rhodium fragments highlight how the nature of the metal fragment and its environment also plays a crucial role in determining the rate of $\mathrm{C}-\mathrm{H}$ activation.

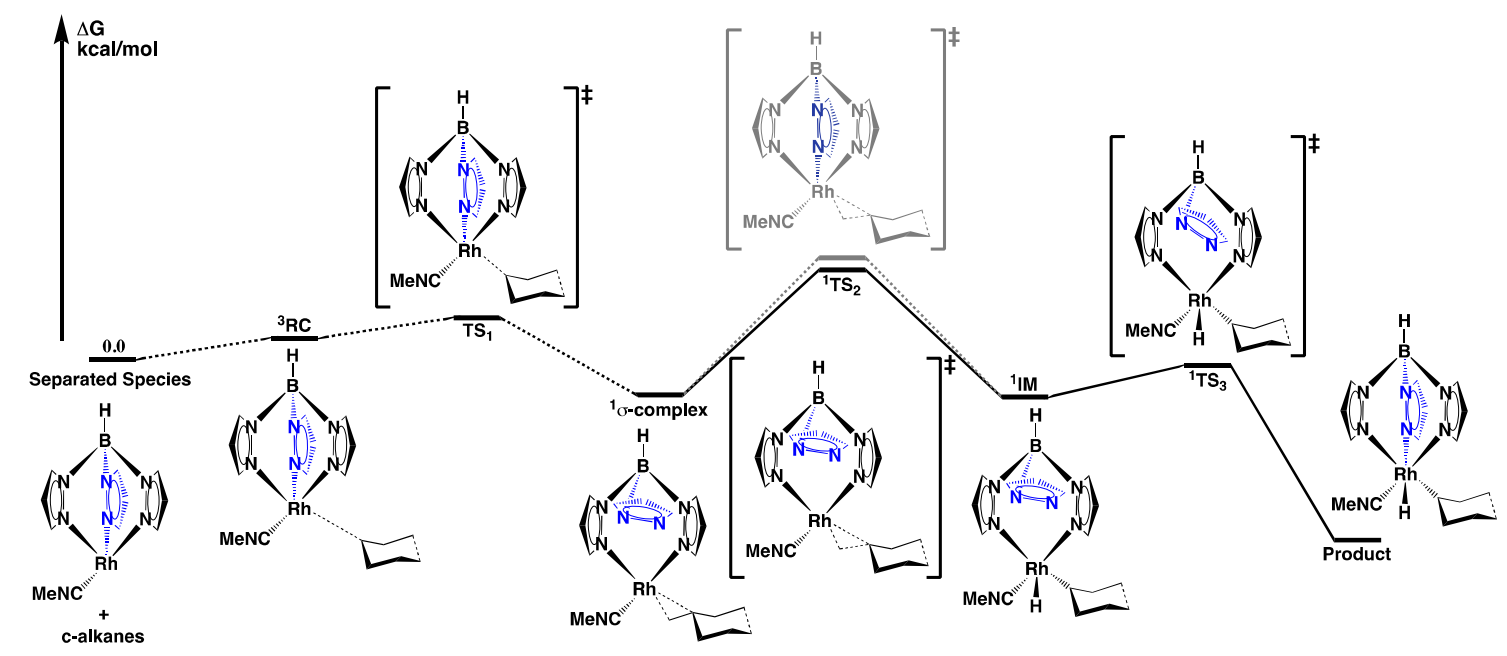

Figure 10: DFT results for the proposed mechanism C-H activation of $c$-alkanes by $\mathrm{TpRh}(\mathrm{CNMe})$. The grey-coloured ${ }^{1} \mathrm{TS}_{2}$ indicates the less stable $\boldsymbol{\kappa}^{3} \mathrm{C}-\mathrm{H}$ activation transition state. 
DFT calculations indicate that the main product of photolysis, the triplet $\kappa^{3}-\mathrm{Tp}$ ' $\mathrm{Rh}(\mathrm{CNMe})$ complex, is in rapid equilibrium with respect to the weak binding of the $c$-alkane $\left({ }^{3} \mathrm{RC}\right.$, an enthalpically stable intermediate, but the free energy favours the free fragment) (Figure 10). Going through a triplet-singlet crossing barrier brings this $\mathrm{Tp}$ ' $\mathrm{Rh}(\mathrm{CNMe})(c$-alkane) complex to a singlet state with one pyrazolyl arm dechelated, which strongly binds the $c$-alkane as the $\kappa^{2}$-б-complex, $\kappa^{2}-\mathrm{Tp}$ 'Rh $(\mathrm{CNMe})(c$-alkane). The conversion barrier of $4.0 \mathrm{kcal} / \mathrm{mol}$ was estimated here, ${ }^{3,5,7}$ which corresponds to the $\mathbf{1}$ to $\mathbf{2}$ decay at $\sim 400 \mathrm{ps}$ in experiment.

Table 6: Relative free energies (lowest/highest in $\mathrm{kcal} / \mathrm{mol}$ ) of DFT calculated species to the separated species (RC) in the proposed mechanism of $\mathrm{TpRh}(\mathrm{CNMe})$ catalysed $\mathrm{C}-\mathrm{H}$ activation of $c$-pentane, $c$-hexane, $c$-heptane, and $c$-octane.

\begin{tabular}{lcccccc}
\hline & Separated Species & ${ }^{1} \kappa^{2}$ - $\sigma$-complex & ${ }^{1} \mathrm{TS}_{2}$ & ${ }^{1} \mathrm{IM}$ & ${ }^{1} \mathrm{TS}_{3}$ & Product \\
\hline$c$-pentane & 0.0 & $-3.6 /-2.5$ & $6.2 / 7.6$ & $-5.1 /-3.2$ & $-2.4 /-1.1$ & $-20.1 /-18.1$ \\
$c$-hexane & 0.0 & $-2.9 /-2.6$ & $6.7 / 7.2$ & $-3.9 /-2.2$ & $-2.1 / 0.7$ & $-20.4 /-16.0$ \\
$c$-heptane & 0.0 & $-4.3 /-2.4$ & $7.4 / 8.2$ & $-3.3 /-1.6$ & $-1.6 / 1.5$ & $-20.0 /-15.2$ \\
$c$-octane & 0.0 & $-4.3 /-2.6$ & $6.9 / 13.4$ & $-3.8 / 4.6$ & $-1.8 / 7.9$ & $-19.2 /-7.7$ \\
\hline
\end{tabular}

Subsequently, the $\kappa^{2}$ - $\sigma$-complex proceeds over the rate-determining $\mathrm{C}-\mathrm{H}$ activation barrier $\left({ }^{1} \mathbf{T S}_{2}\right.$ in Figure 10) which ranges from of 9.6-11.7 kcal/mol (Table 6) to render the alkyl hydride with $\mathrm{Tp}$ in the $\kappa^{2}$ conformation; finally, the dechelated pyrazolyl rechelates to the $\mathrm{Rh}$ via a very shallow barrier $\left({ }^{\mathbf{1}} \mathbf{T S}_{\mathbf{3}}\right)$ to form the final product. 


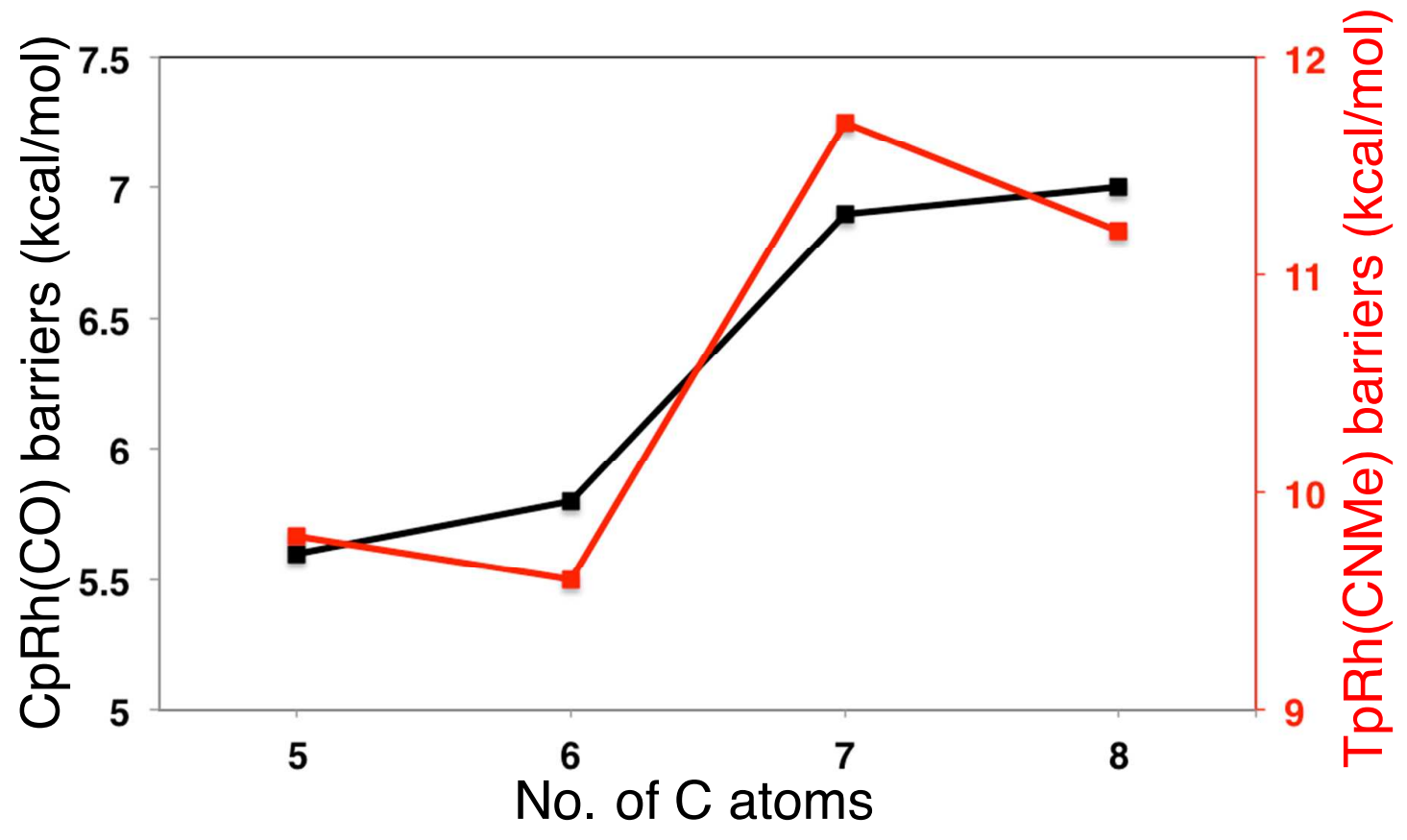

Figure 11: Calculated C-H bond activation barriers for the four cycloalkanes catalysed by TpRh(CNMe) (red) and CpRh(CO) (black).

In contrast to the barrier of $8.1 \mathrm{kcal} / \mathrm{mol}$ calculated for the activation of $n$-heptane, the barriers of activating $c$-alkanes are in the range of $9.6-11.7 \mathrm{kcal} / \mathrm{mol}$, which correlates with the measured lifetimes of $\sim 20 \mathrm{~ns}$ and more than $200 \mathrm{~ns}$, respectively. This difference can be attributed to a combination of the larger barrier for the secondary $\mathrm{C}-\mathrm{H}$ bond activation in $c$ alkanes vs the primary $\mathrm{C}$ - $\mathrm{H}$ bond activation in $n$-heptane and the greater steric hindrance between the $\mathrm{TpRh}(\mathrm{CNMe})$ residue and the cyclic alkane than that of the linear alkane, which contributes to the increase in lifetimes from $c$-pentane to $c$-octane, as shown in Figure 8, while those of $n$-pentane to $n$-nonane do not change as much (see Table $\mathbf{S 2}$ and Figure $\mathbf{S 1}$ in SI ). 

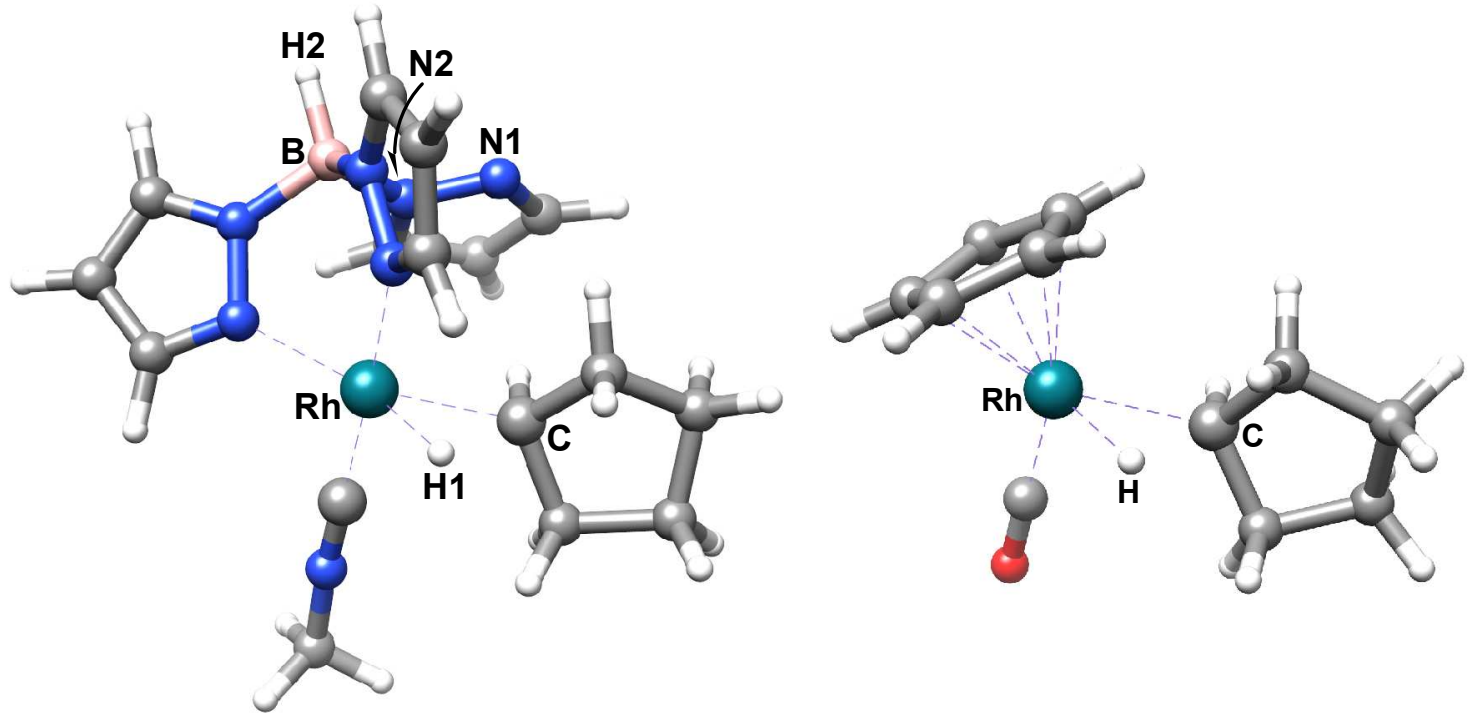

Figure 12: Sampled optimized geometries of the C-H activation TSs catalysed by TpRh(CNMe) and $\mathrm{CpRh}(\mathrm{CO})$, respectively.

Table 7: Geometric parameters of the lowest-energy $\sigma$-complexes and activation TSs in $\mathrm{TpRh}(\mathrm{CNMe})$ and $\mathrm{CpRh}(\mathrm{CO})$ catalysed $\mathrm{C}$-H activation step of $c$-pentane, $c$-hexane, $c$-heptane, and $c$-octane, respectively.

\begin{tabular}{|c|c|c|c|c|c|c|c|c|c|c|c|}
\hline & \multicolumn{8}{|c|}{ TpRh(CNMe) } & \multirow{2}{*}{\multicolumn{3}{|c|}{$\frac{\mathbf{C p R h}(\mathbf{C O})}{\mathrm{TS}_{\text {activation }}}$}} \\
\hline & \multicolumn{4}{|c|}{$\sigma$-complex } & \multicolumn{4}{|c|}{$\mathrm{TS}_{\text {activation }}$} & & & \\
\hline & ${ }^{a} \mathbf{B}_{\mathrm{C}-\mathrm{H} 1}$ & $\mathbf{B}_{\mathrm{Rh}-\mathrm{H} 1}$ & B $_{\text {Rh-C }}$ & ${ }^{b} \mathbf{D}$ & $\mathbf{B}_{\mathrm{C}-\mathrm{H} 1}$ & $B_{\text {Rh-H1 }}$ & $B_{\mathrm{Rh}-\mathrm{C}}$ & D & $\mathbf{B}_{\mathrm{C}-\mathrm{H}}$ & $\mathbf{B}_{\mathrm{Rh}-\mathrm{H}}$ & $\mathbf{B}_{\mathrm{Rh}-\mathrm{C}}$ \\
\hline$c$-pentane & 1.144 & 1.848 & 2.386 & 89.12 & 1.586 & 1.551 & 2.110 & 79.84 & 1.461 & 1.576 & 2.191 \\
\hline$c$-hexane & 1.147 & 1.847 & 2.448 & 89.30 & 1.607 & 1.552 & 2.140 & 79.59 & 1.480 & 1.577 & 2.212 \\
\hline$c$-heptane & 1.142 & 1.881 & 2.439 & 87.31 & 1.634 & 1.551 & 2.142 & 76.98 & 1.507 & 1.573 & 2.214 \\
\hline$c$-octane & 1.148 & 1.878 & 2.465 & 89.31 & 1.631 & 1.553 & 2.146 & 74.19 & 1.489 & 1.576 & 2.219 \\
\hline
\end{tabular}

${ }^{a} \mathrm{~B}$ : bond length, in $\AA ;{ }^{b} \mathrm{D}$ : dihedral angle $\mathrm{D}_{\mathrm{N} 1-\mathrm{N} 2-\mathrm{B}-\mathrm{H} 2}$, in ${ }^{\circ}$.

The plot (Figure 11) of the calculated barriers for the lowest energy pathways in the series of $c$-alkanes activated by $\mathrm{TpRh}(\mathrm{CNMe})$ produces the trend like that seen in the experiment, especially a pronounced step from $c$-hexane to $c$-heptane, but they do not correctly reproduce 
the much smaller difference between $c$-pentane and $c$-hexane or between $c$-heptane and $c$ octane. A similar increasing trend was also calculated for $\mathrm{CpRh}(\mathrm{CO})$, although the lifetime difference between $c$-hexane and $c$-heptane is not as dramatic as that for $\operatorname{TpRh}(\mathrm{CNMe})$ (Figure 11). Table 7 summarizes the $\mathrm{C}-\mathrm{H}, \mathrm{Rh}-\mathrm{H}$, and $\mathrm{Rh}-\mathrm{C}$ bond lengths in the lowest activation TSs of the four $c$-alkanes by $\mathrm{TpRh}(\mathrm{CNMe})$ and $\mathrm{CpRh}(\mathrm{CO})$, respectively, as shown in Figure 12. The much longer $\mathrm{C}-\mathrm{H}$ bonds and shorter $\mathrm{Rh}-\mathrm{H}$ and $\mathrm{Rh}-\mathrm{C}$ bonds in the $\mathrm{TpRh}(\mathrm{CNMe})$ transition state (TS) than those in the $\mathrm{CpRh}(\mathrm{CO}) \mathrm{TS}$ indicate a later TS for $\mathrm{TpRh}(\mathrm{CNMe})$ in comparison to $\mathrm{CpRh}(\mathrm{CO})$, consistent with the former's higher barrier, as more geometric distortion is needed before the electronic rearrangement begins to stabilize the energy. ${ }^{16}$

Table 8: Calculated ranges of activation and methylene migration barriers (lowest/highest) in the $\mathrm{C}$-H activation of $c$-pentane, $c$-hexane, $c$-heptane, and $c$-octane.

\begin{tabular}{ccc}
\hline & Activation Barriers & Migration Barriers $^{a}$ \\
\hline$c$-pentane & $9.8 / 10.1$ & $6.7 / 7.8$ \\
$c$-hexane & $9.6 / 9.8$ & $6.2 / 6.5$ \\
$c$-heptane & $10.3 / 11.6$ & $4.5 / 8.0$ \\
$c$-octane & $9.8 / 16.0$ & $5.4 / 8.7$
\end{tabular}

${ }^{a}$ Much lower barriers $(<2 \mathrm{kcal} / \mathrm{mol})$ for 1,1-migrations between the two $\mathrm{H}$ atoms on the same $\mathrm{C}$ are not listed.

As reported in our previous study on the $\mathrm{CpRh}(\mathrm{CO})$ (alkane) activations, ${ }^{5}$ ring-migration can play a role in influencing the rate of $\mathrm{C}-\mathrm{H}$ activation. The numerous migration barriers (TSs) between different $\kappa^{2}-\sigma$-complexes have been located for the $\mathrm{TpRh}(\mathrm{CNMe})(\mathrm{c}$-alkane) systems and these always have lower barriers than the activation (Table 8), which facilitates the $\mathrm{C}-\mathrm{H}$ activation to proceed via the lowest energy pathway, i.e. from the most stable $\kappa^{2}-\sigma$-complex over the lowest $\mathrm{C}-\mathrm{H}$ activation TS even if this TS involves a migration to a different $\mathrm{CH}_{2}$ 
group. Thus, the kinetics of the entire $\mathrm{C}-\mathrm{H}$ reaction are dominated by the $\mathrm{C}-\mathrm{H}$ activation barriers $\left({ }^{1} \mathbf{T S}_{2}\right)$, like the $\mathrm{CpRh}(\mathrm{CO})$ case.

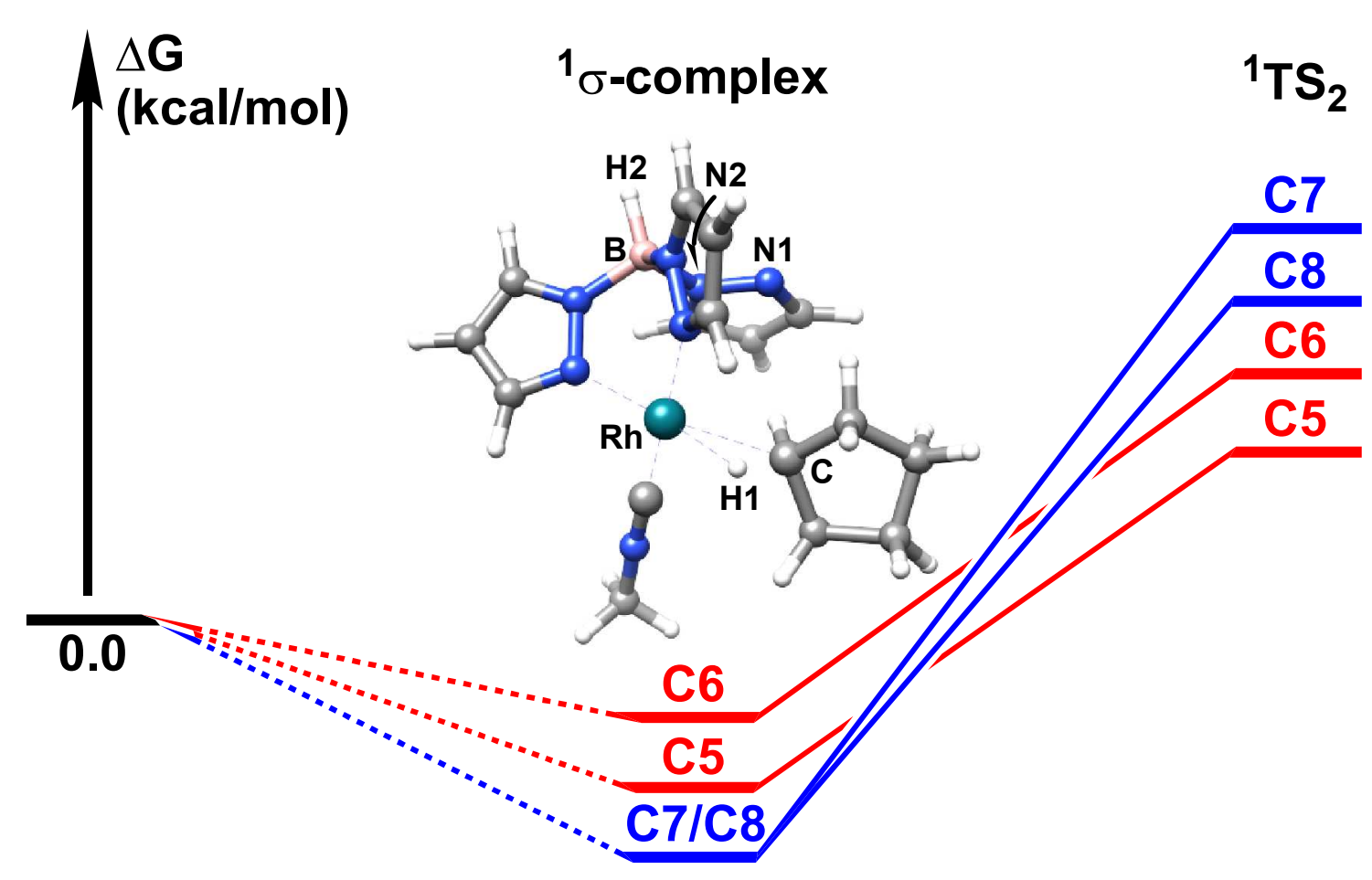

Figure 13: Comparative illustration of the relative energies of the rate-determining step of $c$ pentane, $c$-hexane (in red), $c$-heptane, and $c$-octane (in blue) activation. Depicted is the optimized geometry of a sampled $\sigma$-complex.

Figure 13 illustrates that the smaller activation barriers in $c$-pentane and $c$-hexane originate from the combination of the relatively high-energy $\sigma$-complexes and the low-energy transition states, whereas in $c$-heptane and $c$-octane the $\sigma$-complexes become more stable and the transition states become more unfavourable, a combination that leads to their larger barriers. Similar enhanced stability of $\sigma$-complexes as a function of the alkane size has been observed in experiments, ${ }^{17}$ and was attributed to the larger number of alkane-metal interaction sites. ${ }^{18}$ Nevertheless, as illustrated in Figure 13 and Table 7, the $\sigma$-complexes in 
$c$-pentane and $c$-hexane have much shorter Rh-H1 bonds (1.848 and $1.847 \AA$ ) than the larger $c$-heptane and $c$-octane $(1.881$ and $1.878 \AA$ ), especially an obvious jump from $1.847 \AA$ in $c$ hexane to $1.881 \AA$ in $c$-heptane, as well as a general trend of longer Rh-C bonds for larger $c$ alkanes from $2.386 \AA$ in $c$-pentane to $2.465 \AA$ in $c$-octane, yet the $\mathrm{C}$-H1 bond lengths are all around $1.145 \AA$. The greater distance between $\mathrm{C}$-H bond of the larger $c$-alkanes and the $\mathrm{Rh}$ should reflect a weaker direct interaction but the overall binding energy is larger. This dilemma is resolved when dispersion is considered as it stabilizes the larger $c$-alkanes at longer distances from the $\mathrm{Rh}$; without dispersion effects the larger $c$-alkanes are bound more weakly. Functionals without dispersion produce weaker binding for larger cycloalkanes, while adding a dispersion correction to these results reverses the trend, as do functionals with built-in dispersion (see Table S4 in SI for additional details). Relative to the $\sigma$-complexes, the TSs require closer proximity of the $c$-alkane and the $\mathrm{Rh}$ in order to cleave the $\mathrm{C}-\mathrm{H}$ bond; here steric hindrance between $c$-alkane skeleton and Tp ligand increases and contributes to the higher barriers for the larger $c$-alkanes. The dihedral angle $\mathrm{D}_{\mathrm{N} 1-\mathrm{N} 2-\mathrm{B}-\mathrm{H} 2}$ reflects the position of the dechelated pyrazolyl arm with respect to its original $\kappa^{3}$ conformation $\left(180^{\circ}\right)$, and the smaller it is, the larger the arm deviates. $\mathrm{D}_{\mathrm{N} 1-\mathrm{N} 2-\mathrm{B}-\mathrm{H} 2}$ should indicate the steric influence of the alkane ring on the Tp ligand, which is another factor that affects the stability of the geometric structures. Thus, $\mathrm{D}_{\mathrm{N} 1-\mathrm{N} 2-\mathrm{B}-\mathrm{H} 2}$ in the $\mathrm{C}-\mathrm{H}$ activation $\mathrm{TSs}\left({ }^{\mathbf{1}} \mathbf{T S}_{\mathbf{2}}\right)$ parallels well the expected steric influence of the c-alkanes.

Table 9: Relative free energies $\left(\Delta G^{\ddagger}{ }_{k 3}-\Delta G^{\ddagger}{ }_{k 2}, \mathrm{kcal} / \mathrm{mol}\right)$ of the $\mathrm{C}-\mathrm{H}$ activation TSs in linear/cyclo heptane catalyzed by $\operatorname{Tp}^{[*]} \mathrm{Rh}(\mathrm{CO})$ and $\mathrm{Tp}^{[*]} \mathrm{Rh}\left(\mathrm{CNR}^{a}\right)$, respectively. ${ }^{d}$

\begin{tabular}{ccc}
\hline & $n$-heptane & $c$-heptane \\
\hline $\mathrm{Tp}^{[*]} \mathrm{Rh}(\mathrm{CO})$ & $-1.7[0.0]^{b}$ & $-0.6[1.0]$ \\
$\mathrm{Tp}^{[*]} \mathrm{Rh}(\mathrm{CNR})$ & $-0.5[0.6]$ & $0.2\left[-^{c}\right]$ \\
\hline
\end{tabular}


${ }^{a} \mathrm{CNR}$ : CNMe group was used as CNR with the Tp ligand and CNneopentyl group with Tp* ligand; ${ }^{b}$ Values in the parentheses indicate the relative free energies in the corresponding $\mathrm{Tp} * \mathrm{Rh}\left(\mathrm{CNneopentyl)} \mathrm{systems;}{ }^{c} \kappa^{3}\right.$-TS for the $\mathrm{C}$-H activation of $c$-heptane by $\mathrm{Tp} * \mathrm{Rh}(\mathrm{CNneopentyl})$ cannot be located due to significant steric hindrance; ${ }^{d}$ Preliminary results using the $\mathrm{Tp} *$ ligand have produced similar trend for the relative energies of $\kappa^{3}$ to $\kappa^{2}$-TSs. Detailed results will be reported in a future contribution.

\section{Conclusions}

TRIR spectroscopy has been successfully utilised to investigate the mechanism of C-H activation by $\mathrm{Tp} * \mathrm{Rh}(\mathrm{CNR})$ in the $v(\mathrm{CNR})$ and $v(\mathrm{~B}-\mathrm{H})$ spectral regions. Intermediate species with matching kinetics were observed in both spectral windows. These were assigned to analogous species to those of the widely studied $\mathrm{Tp} * \mathrm{Rh}(\mathrm{CO}) \mathrm{C}-\mathrm{H}$ activation mechanism: ${ }^{6-8}$ $\kappa^{3}-\eta^{1}$-alkane complex (1); $\kappa^{2}-\eta^{2}$-alkane complex (2); and $\kappa^{3}$-alkyl hydride (3). Identification of the intermediates in the $v(\mathrm{~B}-\mathrm{H})$ spectral region afforded direct evidence that $\mathbf{1}$ and $\mathbf{3}$ are in a $\kappa^{3}$-configuration, while 2 is in a $\kappa^{2}$-configuration since the $v(B-H)$ stretch is very characteristic of the environment of the Tp' ligand. ${ }^{13}$ DFT calculations support the assignment of these species with optimised structures and calculated frequencies for all the intermediates observed, including several low-concentration intermediates seen at very short times, in which the carbodiimide has recoiled rather than replaced by the cycloalkane. Calculations predict that the photolysis product (1) is a triplet $\kappa^{3}-\mathrm{Tp}$ ' $\mathrm{Rh}(\mathrm{CNR})$ residue that only weakly binds the alkane as an $\eta^{1}$-alkane, as indicated by a long $\mathrm{Rh}-\mathrm{H} 1$ contact in its optimized geometry. Subsequently, 1 dechelates one pyrazolyl arm to form $\kappa^{2}-\mathrm{Tp}$ 'Rh $(\mathrm{CNR})\left(\eta^{2}\right.$-alkane) with a strongly bound alkane, a singlet $\sigma$-complex with short $\mathrm{Rh}$ $\mathrm{H} 1$ and $\mathrm{Rh}-\mathrm{C} 1$ contacts and a stretched $\mathrm{C} 1-\mathrm{H} 1$. Intermediate 2 proceeds over the ratedetermining $\mathrm{C}-\mathrm{H}$ activation barrier to give the final product 3. Good agreement has been made between their calculated frequencies and those observed experimentally. 
Room temperature $\mathrm{C}-\mathrm{H}$ activation rates were measured for $\mathrm{Tp} * \mathrm{Rh}(\mathrm{CNR})($ cycloalkane) and also for $\mathrm{Tp} * \mathrm{Rh}(\mathrm{CO})\left(\right.$ cycloalkane) for comparison to each other, as well as to the $\mathrm{Cp}$ and $\mathrm{Cp}^{*}$ fragments examined previously. The lifetime trends for the $\mathrm{C}-\mathrm{H}$ activation of the cyclic alkanes by all four rhodium fragments displayed similar step-like behaviour, showing the subtle control that the alkane has on the rate of $\mathrm{C}-\mathrm{H}$ activation. As for the $\mathrm{Cp}$ and $\mathrm{Cp}^{*}$ rhodium fragments, this control is thought to be a result of a number of discrete $\sigma$-complexes for each cyclic alkane, all with different activation barriers and various possible ring migrations between these $\sigma$-complexes. The large change occurs between cyclohexane and cycloheptane because the latter has a much larger number of more stable $\sigma$-complexes and more sterically crowded higher-energy transition states.

However, there were differences between the rhodium fragments in terms of their absolute lifetimes. This clearly demonstrates that the specific ligand environment has a much more significant influence on the absolute rate of $\mathrm{C}-\mathrm{H}$ activation. Much slower rates of $\mathrm{C}-\mathrm{H}$ activation with the cyclic alkanes were measured for the $\mathrm{Tp} * \mathrm{Rh}(\mathrm{CNR})$ and $\mathrm{Tp} * \mathrm{Rh}(\mathrm{CO})$ fragments compared to the $\mathrm{CpRh}(\mathrm{CO})$ and $\mathrm{Cp} * \mathrm{Rh}(\mathrm{CO})$ fragments. This fits with the previous report of how dechelation of the Tp's third pyrazolyl arm stabilizes the 4-coordinate, squareplanar $\kappa^{2}-\eta^{2}$-alkane complex and reduces the electron density available for the oxidative addition of the $\mathrm{C}-\mathrm{H}$ bond. ${ }^{8}$ The DFT calculations here show that the key, rate-determining $\mathrm{C}-\mathrm{H}$ activation step in the more crowded cyclic alkanes may occur before the rechelation of the third pyrazolyl arm, while for the less crowded linear alkane rechelation is predicted to proceed first and lower the activation barrier.

Furthermore, the rates of $\mathrm{C}-\mathrm{H}$ activation for the $\mathrm{Tp} * \mathrm{Rh}(\mathrm{CNR})$ fragment compared to the closely related $\mathrm{Tp} * \mathrm{Rh}(\mathrm{CO})$ fragment are similar for small cycloalkanes as the extra steric bulk of the neopentyl isocyanide ligand is offset by the higher Rh electron density from the weaker backbonding of the CNR ligand. However, the extra steric bulk of the neopentyl 
isocyanide ligand, along with the already bulky Tp* ligand, may hinder the rechelation of the Tp' arm, ${ }^{8}$ such that the C-H activation takes place over a barrier without the assistance of the rechelation.

Table 9 compares the relative energies of the $\kappa^{3}$-TSs, where the third pyrazolyl arm rechelates before the TS, and the $\kappa^{2}$-TSs, where $\mathrm{C}-\mathrm{H}$ activation occurs before the third pyrazolyl arm rechelates. In the case of linear alkanes, where primary $\mathrm{C}-\mathrm{H}$ bonds are activated, the calculations predict that $\kappa^{3}$-TSs are strongly favoured over the corresponding $\kappa^{2}$-TSs for $\mathrm{Tp}$ ' $\mathrm{Rh}(\mathrm{CO})$, where $\mathrm{Rh}$ needs the additional electron density from the rechelation because of the strong backbonding by $\mathrm{CO}$, while $\kappa^{3}$-TSs are only weakly favoured over the corresponding $\kappa^{2}$-TSs for Tp'Rh(CNMe), where the poorer backbonding CNR ligand leaves the $\mathrm{Rh}$ with more electron density. However, in the case of cycloalkanes, the scenario bifurcates, where $\kappa^{3}$-TSs are only weakly preferred in Tp'Rh(CO) activation because now the greater steric bulk of the cycloalkanes raises the relative energy of the $\kappa^{3}$-TSs, while finally in Tp'Rh(CNR) the combination of a more electron-rich $\mathrm{Rh}$ and less steric crowding in the $\kappa^{2}$-TSs renders them more stable than the $\kappa^{3}$-TSs. Thus, the balance between the sterics and the electronics in the reactive species tunes the preference of $\kappa^{2}$ - or $\kappa^{3}$-TS geometries, where the carbon skeleton of cycloalkanes favors the dechelation of the pyrazol arm to reduce sterics while the electron-withdrawing ligand $\mathrm{CO}$ facilitates the rechelation of the pyrazol arm to the $\mathrm{Rh}$ to promote the oxidative addition of the $\mathrm{C}-\mathrm{H}$ bonds. Thus, the less sterically demanding linear alkanes always favor rechelation of the pyrazol arm before the C-H activation.

\section{Experimental}

$\mathrm{Tp}^{\prime} \mathrm{Rh}(\mathrm{CNR})(\text { carbodiimide })^{9}$ and $\mathrm{Tp}{ }^{\prime} \mathrm{Rh}(\mathrm{CO})_{2}{ }^{19,20}$ were synthesised via adapted literature procedures. The following solvents were all dried over $\mathrm{CaH}_{2}$ under an argon atmosphere prior 
to use: $c$-pentane (Sigma Aldrich, $\geq 99 \%$ ); $c$-hexane (Sigma Aldrich, $\geq 99.9 \%$ ); $c$-heptane (Alfa Aesar, 99\%); c-octane (Alfa Aesar, 99\%); n-pentane (Alfa Aesar, 99+\%); $n$-hexane (Sigma Aldrich, $\geq 99 \%$ ); $n$-heptane (Sigma Aldrich, 99\%); $n$-octane (Lancaster, 99\%) and n-nonane (Sigma Aldrich).

For the TRIR experiments a recirculating flow system consisting of a peristaltic pump, Teflon tubing, and an infrared solution cell (Harrick Corp.) with $\mathrm{CaF}_{2}$ windows ( $25 \times 2 \mathrm{~mm}$, Crystran) typically at a pathlength of $0.5 \mathrm{~mm}$ was used. The samples were placed under a positive pressure of argon. The TRIR experiments were performed at the ULTRA facility at the Rutherford Appleton Laboratory, which has been discussed in detail elsewhere, ${ }^{21}$ therefore, only a brief summary is given here. A Ti:sapphire laser amplifier (Thales Laser) produces $800 \mathrm{~nm}$ laser pulses $(0.8 \mathrm{~mJ}, 10 \mathrm{kHz}$ with a pulsewidth of $50 \mathrm{fs})$. This laser output is split and one portion is used to generate the $267 \mathrm{~nm}$ pump beam by harmonic generation. The second portion is sent through an optical parametric amplifier (Light Conversion) and a difference frequency generator to produce a tuneable mid-IR probe. The diameter of the pump and probe beams were around $150 \mu \mathrm{m}$ and $80 \mu \mathrm{m}$, respectively. After transmission through the sample, the IR probe is dispersed onto two linear 128 element MCT detector arrays (Infrared Associates). By the use of a chopper, the pump-on and pump-off infrared intensities can be measured and difference spectra generated. A small portion of the IR probe beam is taken before the sample and dispersed onto a 64 element MCT detector array (Infrared Associates) to provide a reference for beam intensity fluctuations. The cell is rastered in the plane perpendicular to the pump and probe beams again and usually the sample is continually flowed through the cell to avoid degradation of the sample.

All the Density Functional-Theory (DFT) calculations were performed with the Gaussian 09 suite of programs. ${ }^{22} \mathrm{MN12SX}$ functional ${ }^{23}$ was employed with using the $6-311++\mathrm{G}^{* * 24,25}$ basis set for the $\mathrm{C}, \mathrm{H}, \mathrm{B}, \mathrm{N}$, and $\mathrm{O}$ atoms, and the Stuttgart quasi-relativistic basis set and 
effective core potential ${ }^{26}$ for Rh. Each species was optimized in the gas phase with tight convergence criteria and on an ultrafine grid as specified in Gaussian 09. Analytical frequency calculations were performed on all optimized structures to ensure that either a minimum or a first-order saddle point was achieved. To decrease the computational time, the methyl groups of Tp'Rh(CNMe)(carbodiimide) were omitted. Scaling factors of 0.928 and 0.970 were used for the calculated frequencies of $v(\mathrm{CNMe})$ and $v(\mathrm{BH})$ regions, respectively. The SI contains the XYZ-Coordinates of the optimized geometries of the key species.

\section{ACKNOWLEDGMENT}

The authors acknowledge financial support of the EPSRC (Grant EP/I01974X to MWG), The Welch Foundation (A-0648 to MBH) for initial support of this work, and the Qatar National Research Fund (NPRP grant 7-297-1-051 to MBH, ENB, and SDZ) for the major support of the computational work. MWG gratefully acknowledges receipt of a support from the University of Nottingham Ningbo China. The authors acknowledge Texas A\&M University’s High Performance Research Computing Facility (http://hprc.tamu.edu/) for providing computing resources useful in conducting the research reported in this paper.

\section{ASSOCIATED CONTENT}

\section{Supporting Information.}

The SI includes: Table S1-Infrared frequencies $\left(\mathrm{cm}^{-1}\right)$ for a number of Tp complexes in $\kappa^{3}$ and $\kappa^{2}$ configurations, Table S2-Lifetimes for the C-H activation of linear alkanes by the different rhodium fragments studied: $\mathrm{CpRh}(\mathrm{CO}) ; \mathrm{Cp} * \mathrm{Rh}(\mathrm{CO}) ; \mathrm{Tp} * \mathrm{Rh}(\mathrm{CNR}) ;$ and $\mathrm{Tp} * \mathrm{Rh}(\mathrm{CO})$, Figure $\mathrm{S} 1-\mathrm{Lifetime}$ trends for the $\mathrm{CpRh}(\mathrm{CO})$ (red), $\mathrm{Cp} * \mathrm{Rh}(\mathrm{CO})$ (orange), $\mathrm{Tp}$ 'Rh(CNR) (blue) and $\mathrm{Tp}$ 'Rh(CO) (green) fragments with the linear alkanes (n-pentane to n-nonane), Table S3-Frequency Scaling Procedure from Calculated to Experimental Values, 
Table S4-Effect of Dispersion Correction on the Stability of $\sigma$-Complexes and XYZ-

Coordinates of key complexes. This material is available free of charge via the Internet at

http://pubs.acs.org

\section{AUTHOR INFORMATION}

Corresponding Authors

mbhall@tamu.edu

Notes

The authors declare no competing financial interest.

\section{References}

(1) (a) Niu, S.; Hall, M. B. Chem. Rev. 2000, 100, 353; (b) Balcells, D.; Clot, E.; Eisenstein, O. Chem. Rev. 2010, 110, 749.

(2) For the studies on C-H activation by Cp' and Tp' rhodium complexes, see (a) Jones, W. D.; Feher, F. J. J. Am. Chem. Soc. 1982, 104, 4240; (b) Janowicz, A. H.; Bergman, R. G. J. Am. Chem. Soc. 1982, 104, 352; (c) Jones, W. D.; Feher, F. J. Organometallics 1983, 2, 562; (d) Jones, W. D.; Feher, F. J. J. Am. Chem. Soc. 1984, 106, 1650; (e) Saillard, J. Y.; Hoffmann, R. J. Am. Chem. Soc. 1984, 106, 2006; (f) Periana, R. A.; Bergman, R. G. Organometallics 1984, 3, 508; (g) Jones, W. D.; Feher, F. J. J. Am. Chem. Soc. 1986, 108, 4814; (h) Ziegler, T.; Tschinke, V.; Fan, L.; Becke, A. D. J. Am. Chem. Soc. 1989, 111, 9177; (i) Belt, S. T.; Grevels, F.-W.; Klotzbücher, W. E.; McCamley, A.; Perutz, R. N. J. Am. Chem.

Soc. 1989, 111, 8373; (j) Jones, W. D.; Feher, F. J. Acc. Chem. Res. 1989, 22, 91; (k) Wasserman, E. P.; Moore, C. B.; Bergman, R. G. Science 1992, 255, 315; (1) Song, J.; Hall, M.

B. Organometallics 1993, 12, 3118; (m) Schultz, R. H.; Bengali, A. A.; Tauber, M. J.; Weiller, B. H.; Wasserman, E. P.; Kyle, K. R.; Moore, C. B.; Bergman, R. G. J. Am. Chem. Soc. 1994, 116, 7369; (n) Siegbahn, P. E. M. J. Am. Chem. Soc. 1996, 118, 1487; (o) Couty, M.; Bayse, C. A.; JiménezCataño, R.; Hall, M. B. J. Phys. Chem. 1996, 100, 13976; (p) Asbury, J. B.; Ghosh, H. N.; Yeston, J. S.; Bergman, R. G.; Lian, T. Q. Organometallics 1998, 17, 3417; (q) Wick, D. D.; Jones, W. D. Organometallics 1999, 18, 495; (r) Asplund, M. C.; Snee, P. T.; Yeston, J. S.; Wilkens, M. J.; Payne, C. K.; Yang, H.; Kotz, K. T.; Frei, H.; Bergman, R. G.; Harris, C. B. J. Am. Chem. Soc. 2002, 124, 10605; (s) Jones, W. D. Acc. Chem. Res. 2003, 36, 140; (t) Vetter, A.

J.; Flaschenriem, C.; Jones, W. D. J. Am. Chem. Soc. 2005, 127, 12315;

(3) George, M. W.; Hall, M. B.; Jina, O. S.; Portius, P.; Sun, X.-Z.; Towrie, M.; Wu, H.; Yang, X.; Zaric, S. D. Proc. Natl. Acad. Sci. U. S. A. 2010, 107, 20178.

(4) George, M. W.; Hall, M. B.; Portius, P.; Renz, A. L.; Sun, X.-Z.; Towrie, M.; Yang, X. Dalton Trans. 2011, 40, 1751. 
(5) Pitts, A. L.; Wriglesworth, A.; Sun, X.-Z.; Calladine, J. A.; Zaric, S. D.; George, M. W.; Hall, M. B. J. Am. Chem. Soc. 2014, 136, 8614.

(6) Lian, T.; Bromberg, S. E.; Yang, H.; Proulx, G.; Bergman, R. G.; Harris, C. B. J. Am. Chem. Soc. 1996, 118, 3769.

(7) (a) Zarić, S.; Hall, M. B. J. Phys. Chem. A, 1998, 102, 1963; (b) Bromberg, S. E.; Yang, H.; Asplund, M. C.; Lian, T.; McNamara, B. K.; Kotz, K. T.; Yeston, J. S.; Wilkens, M.; Frei, H.; Bergman, R. G.; Harris, C. B. Science 1997, 278, 260.

(8) Blake, A. J.; George, M. W.; Hall, M. B.; McMaster, J.; Portius, P.; Sun, X. Z.; Towrie, M.; Webster, C. E.; Wilson, C.; Zaric, S. D. Organometallics 2008, 27, 189.

(9) (a) Jones, W. D.; Duttweiler, R. P.; Feher, F. J.; Hessell, E. T. Nouv. J. Chem. 1989, 13, 725. (b) Hessell, E. T.; Jones, W. D. Organometallics 1992, 11, 1496.

(10) Jones, W. D.; Hessell, E. T. J. Am. Chem. Soc. 1993, 115, 554.

(11) Northcutt, T. O.; Wick, D. D.; Vetter, A. J. Jones, W. D. J. Am. Chem. Soc. 2001, $123,7257$.

(12) Clot, E.; Eisenstein, O.; Jones, W. D. Proc. Natl. Acad. Sci. U. S. A. 2007, 104, 6939.

(13) (a) Akita, M.; Ohta, K.; Takahashi, Y.; Hikichi, S.; Morooka, Y. Organometallics 1997, 16, 4121; (b) Northcutt, T. O.; Lachicotte, R. J.; Jones, W. D. Organometallics 1998, $17,5148$.

(14) Kaesz, H. D.; Saillant, R. B. Chem. Rev. 1972, 72, 231.

(15) (a) Bernskoetter, W. H.; Schauer, C. K.; Goldberg, K. I.; Brookhart, M. Science 2009, 326, 553. (b) Pike, S. D.; Thompson, A. L.; Algarra, A. G.; Apperley, D. C.; Macgregor, S. A.; Weller, A. S. Science 2012, 337, 1648; (c) Pike, S. D.; Chadwick, F. M.; Rees, N. H.; Scott, M. P.; Weller, A. S.; Krämer, T.; Macgregor, S. A. J. Am. Chem. Soc. 2015, 137, 820; (d) Chadwick, F. M.; Krämer, T.; Guttmann, T.; Rees, N. H.; Thompson, A. L.; Edwards, A. J.; Buntkowsky, G.; Macgregor, S. A.; Weller, A. S. J. Am. Chem. Soc. 2016, 138, 13369; (e) McKay, A. I.; Krämer, T.; Rees, N. H.; Thompson, A. L.; Christensen, K. E.; Macgregor, S. A.; Weller, A. S. Organometallics, 2017, 36, 22.

(16) Politzer, P., Toro-Labbé, A., Gutiérrez-Oliva, S., Murray, J.S. Adv. in Quant. Chem., 2012, 64, 189 and references therein.

(17) (a) Brown, C. E.; Ishikawa, Y.; Hackett, P. A.; Rayner, D. M. J. Am. Chem. Soc.1990, 112, 2530. (b) McNamara, B. K.; Yeston, J. S.; Bergman, R. G.; Moore, C. B. J. Am. Chem. Soc. 1999, 121, 6437. (c) Childs, G. I.; Colley, C. S.; Dyer, J.; Grills, D. C.; Sun, X.-Z.; Yang, J. X.; George, M. W. J. Chem. Soc., Dalton Trans. 2000, 0, 1901.

(18) Cobar, E. A.; Khaliullin, R. Z.; Bergman, R. G.; Head-Gordon, M. Proc. Natl. Acad. Sci. U.S.A. 2007, 104, 6963.

(19) May, S.; Reinsalu, P.; Powell, J. Inorg. Chem. 1980, 19, 1582.

(20) Trofimenko, S. J. Am. Chem. Soc. 1967, 89, 6288.

(21) Greetham, G. M.; Burgos, P.; Cao, Q.; Clark, I. P.; Codd, P. S.; Farrow, R. C.; George, M. W.; Kogimtzis, M.; Matousek, P.; Parker, A. W.; Pollard, M. R.; Robinson, D. A.; Xin, Z.-J.; Towrie, M. Appl. Spectrosc. 2010, 64, 1311.

(22) Frisch, M. J.; Trucks, G. W.; Schlegel, H. B.; Scuseria, G. E.; Robb, M. A.; Cheeseman, J. R.; Scalmani, G.; Barone, V.; Mennucci, B.; Petersson, G. A.; Nakatsuji, H.; Caricato, M.; Li, X.; Hratchian, H. P.; Izmaylov, A. F.; Bloino, J.; Zheng, G.; Sonnenberg, J. L.; Hada, M.; Ehara, M.; Toyota, K.; Fukuda, R.; Hasegawa, J.; Ishida, M.; Nakajima, T.; Honda, Y.; Kitao, O.; Nakai, H.; Vreven, T.; Montgomery, J. A., Jr.; Peralta, J. E.; Ogliaro, F.; Bearpark, M; Heyd, J. J.; Brothers, E.; Kudin, K. N.; Staroverov, V. N.; Kobayashi, R.; Normand, J.; Raghavachari, K.; Rendell, A.; Burant, J. C.; Iyengar, S. S; Tomasi, J.; Cossi, M.; Rega, N.; Millam, J. M.; Klene, M.; Knox, J. E.; Cross, J. B.; Bakken, V.; Adamo, C.; Jaramillo, J.; Gomperts, R.; Stratmann, R. E.; Yazyev, O.; Austin, A. J.; Cammi, R.; Pomelli, C.; Ochterski, J. W.; Martin, R. L.; Morokuma, K.; Zakrzewski, V. G.; Voth, G. A.; Salvador, P.; Dannenberg, J. J.; Dapprich, S.; Daniels, A. D.; Farkas, O.; Foresman, J. B.; Ortiz, J. V.; Cioslowski, J.; Fox, D. J. Gaussian 09, revision D. 01; Gaussian, Inc.: Wallingford, CT, 2013.

(23) Peverati, R.; Truhlar, D. G. Phys. Chem. Chem. Phys. 2012, 14, 16187.

(24) (a) Krishnan, R.; Binkley, J. S.; Seeger, R.; Pople, J. A. J. Chem. Phys. 1980, 72, 650. (b) McLean, A. D.; Chandler, G. S. J. Chem. Phys. 1980, 72, 5639.

(25) Clark, T.; Chandrasekhar, J.; Spitznagel, G. W.; Schleyer, P. v. R. J. Comput. Chem. 
1983, 4, 294.

(26) (a) Andrae, D.; Haeussermann, U.; Dolg, M.; Stoll, H.; Preuss, H. Theor. Chim. Acta 1990, 77, 123. (b) Martin, J.M.L.; Sundermann, A. J. Chem. Phys. 2001, 114, 3408.

(27) Kitajima, N.; Singh, U. P.; Amagai, H.; Osawa, M.; Morooka, Y. J. Am. Chem. Soc. $1991,113,7757$.

(28) Kitajima, N.; Tamura, N.; Tanaka, M.; Morooka, Y. Inorg. Chem. 1992, 31, 3342.

(29) Kitajima, N.; Hikichi, S.; Tanaka, M.; Morooka, Y. J. Am. Chem. Soc. 1993, 115,

5496.

(30) Kitajima, N.; Fujisawa, K.; Fujimoto, C.; Morooka, Y.; Hashimoto, S.; Kitagawa, T.; Toriumi, K.; Tatsumi, K.; Nakamura, A. J. Am. Chem. Soc. 1992, 114, 1277.

(31) Ito, M.; Amagai, H.; Fukui, H.; Kitajima, N.; MoroOka, Y. Bull. Chem. Soc. Jpn. 1996, 69, 1937 


\section{TOC GRAPHIC}

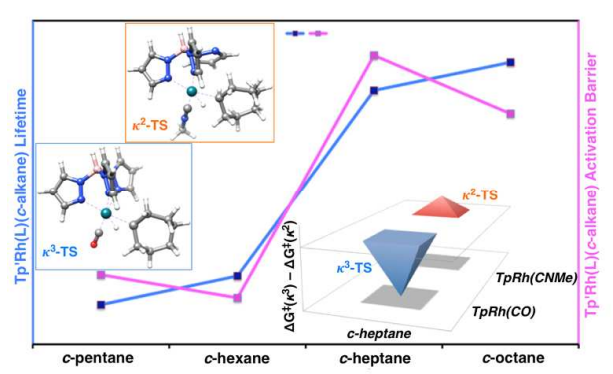

